San Jose State University

SJSU ScholarWorks

Master's Theses

Master's Theses and Graduate Research

2003

\title{
Thickness measurement of diamond-like carbon (DLC) by auger electron spectroscopy (AES)
}

Ying Zheng

San Jose State University

Follow this and additional works at: https://scholarworks.sjsu.edu/etd_theses

\section{Recommended Citation}

Zheng, Ying, "Thickness measurement of diamond-like carbon (DLC) by auger electron spectroscopy (AES)" (2003). Master's Theses. 2483.

DOI: https://doi.org/10.31979/etd.j3df-gc6w

https://scholarworks.sjsu.edu/etd_theses/2483

This Thesis is brought to you for free and open access by the Master's Theses and Graduate Research at SJSU ScholarWorks. It has been accepted for inclusion in Master's Theses by an authorized administrator of SJSU ScholarWorks. For more information, please contact scholarworks@sjsu.edu. 


\title{
THICKNESS MEASUREMENT OF DIAMOND-LIKE CARBON (DLC) BY AUGER ELECTRON SPECTROSCOPY (AES)
}

\author{
A Thesis \\ Presented to \\ The Faculty of the Department of Chemical and Materials Engineering \\ San Jose State University \\ In Partial Fulfillment \\ of the Requirements for the Degree \\ Master of Science
}

by

Ying Zheng

December 2003 
UMI Number: 1418712

\section{INFORMATION TO USERS}

The quality of this reproduction is dependent upon the quality of the copy submitted. Broken or indistinct print, colored or poor quality illustrations and photographs, print bleed-through, substandard margins, and improper alignment can adversely affect reproduction.

In the unlikely event that the author did not send a complete manuscript and there are missing pages, these will be noted. Also, if unauthorized copyright material had to be removed, a note will indicate the deletion.

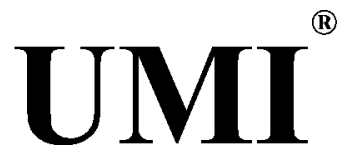

UMI Microform 1418712

Copyright 2004 by ProQuest Information and Learning Company.

All rights reserved. This microform edition is protected against unauthorized copying under Title 17, United States Code.

ProQuest Information and Learning Company 300 North Zeeb Road

P.O. Box 1346

Ann Arbor, MI 48106-1346 
(C) 2003

Ying Zheng

ALL RIGHTS RESERVED 
APPROVED FOR THE DEPARTMENT OF CHEMICAL and MATERIALS ENGINEERING

Gina Selvaduray

Dr. Make Cor

Dr. Manfred Canto

Bill Lu

Dr. Bill Lu, Seagate Materials Microscopy Lab

APPROVED FOR THE UNIVERSITY

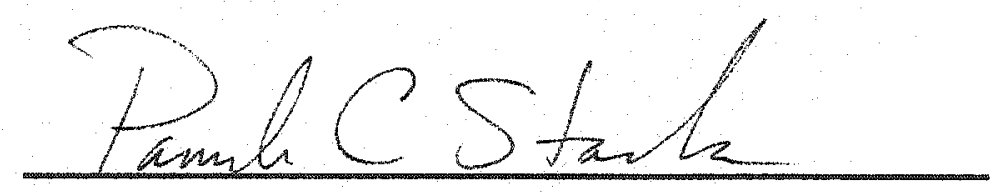




\section{ABSTRACT \\ THICKNESS MEASUREMENT OF DIAMOND-LIKE CARBON (DLC) BY AUGER ELECTRON SPECTROSCOPY (AES)}

By Ying Zheng

To increase the density of magnetic recoding disks and to protect the magnetic layers from sliding contact and corrosion, it is important to be able to accurately measure the thickness of DLC films. The ability to use AES to measure the DLC thickness on magnetic recording disks was studied. The principle of DLC thickness measurement was based on Beer-Lambert's law. The approach was to construct a working curve by using the thickness of DLC measured by ESCA and the intensities of the carbon and cobalt signals detected by AES to generate the calibration parameter "a". This study demonstrated that the DLC thickness could be measured by AES, employing the intensities of the cobalt signal present in the magnetic layer. The maximum measurable DLC thickness was approximately $58 \AA$. Statistical analyses verified that there were no significant differences between the DLC thickness measured by ESCA and those measured by AES. 


\section{ACKNOWLEDGEMENT}

The author thanks her advisor, Dr. Guna S. Selvaduray, her reading committee members, Dr. Manfred Cantow and Dr. Bill Lu, for their guidance and constructive suggestions in the completion of this thesis.

The author also thanks Dr. Gunter Barth, Dr. Bin Zhang, and Dr. Vincent Crist for their assistance with literature materials, ESCA data collection, and for their help in coping with the English language, which made this study possible.

The author is grateful to Mr. Ikeo Nobuyuki of JEOL for his helpful assistance and valuable suggestions with the techniques and applications of Auger electron spectroscopy.

Finally, the author greatly appreciates her family and friends for their long time encouragement and support. 


\section{TABLE OF CONTENTS}

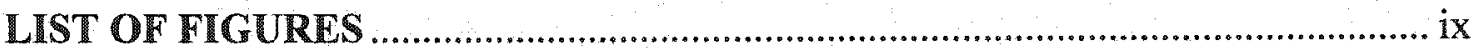

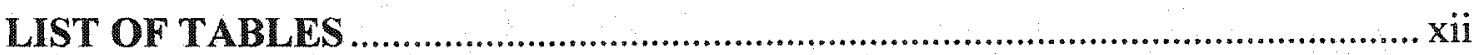

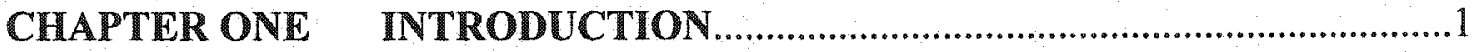

CHAPTER TWO LITERATURE REVIEW .............................................

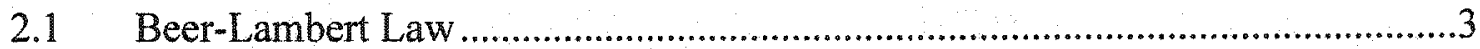

2.2 Diamond-Like Carbon and Its Properties and Application on the

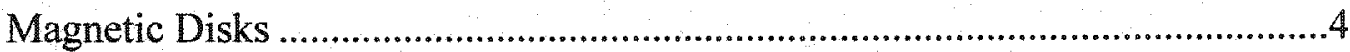

2.3 Thickness Measurement of the Carbon Overcoat by Correlating

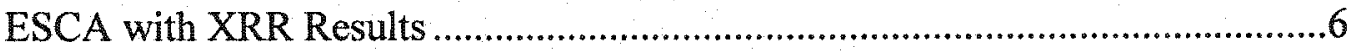

2.4 Carbon Thickness Measured by ESCA and TEM .........................................9

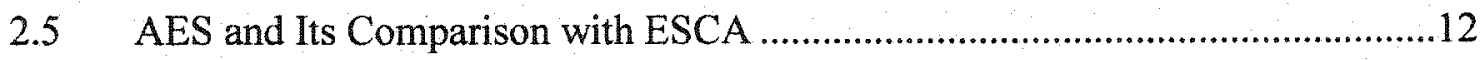

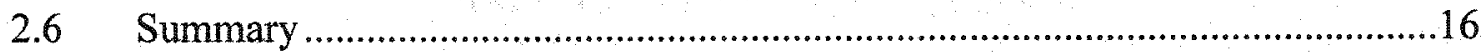

CHAPTER THREE PROJECT HYPOTHESIS AND OBJECTIVES .................18

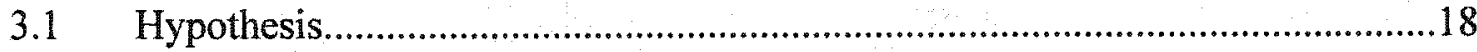

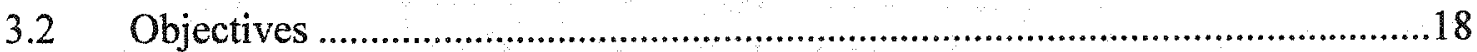

CHAPTER FOUR EXPERIMENTAL DESIGN AND APPARATUS..............19

4.1 Diagrams of Experimental Design ......................................................19

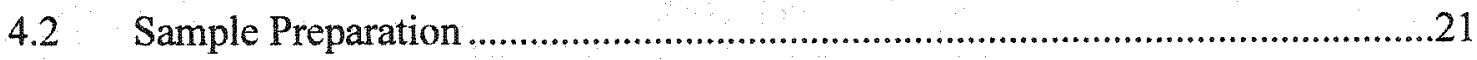

4.3 Electron Spectroscopy for Chemical Analysis (ESCA)...............................23

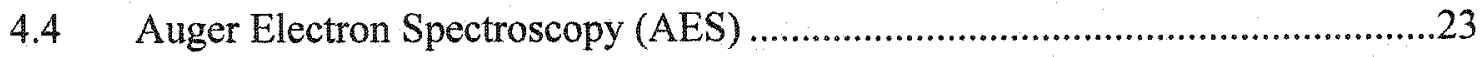

4.5 Calculation of the DLC Thickness.........................................................23 
4.5.1 Carbon and Cobalt Signals from the DLC and Magnetic Layer...........24

4.5.2 Cobalt Signals from the Magnetic Layer Only ................................25

4.5.3 Carbon Signals from the DLC Film Only ......................................26

4.6 Verification and Statistical Analysis on the DLC Thickness

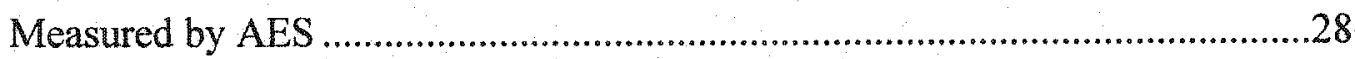

4.6.1 Verification of the DLC Thickness Measured by AES ......................28

4.6.2 Statistical Analysis on the Difference in the DLC Thickness

Measured by ESCA and AES ..................................................28

4.6.3 Variability of the DLC Thickness between Disks ...............................30

4.7 Maximum Measurable DLC Thickness ....................................................30

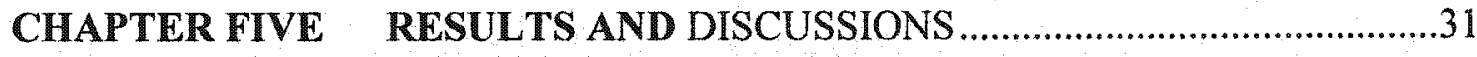

5.1 Intensity of the Carbon Signal Measured by AES ........................................ 31

5.2 The Change of the Intensity of Cobalt Signal with DLC Thickness

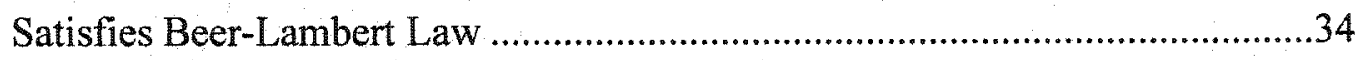

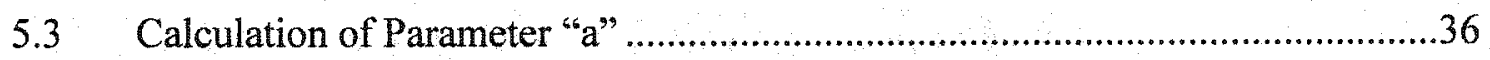

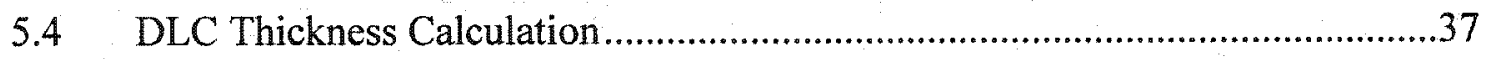

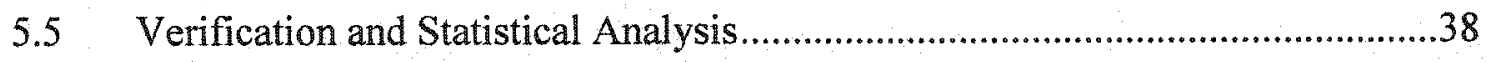

5.5.1 AES DLC Thickness Verification ...............................................38

5.5.2 Statistical Analysis on the Difference in the DLC Thickness

Measured by ESCA and AES ..................................................39

5.5.3 Variability of the DLC Thickness between the Disks .........................40

5.6 Maximum Measurable DLC Thickness .....................................................44 


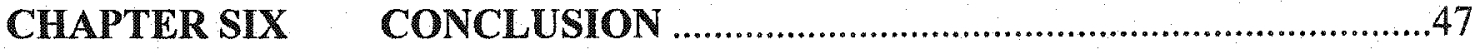

CHAPTER SEVEN RECOMMENDATIONS ............................................49

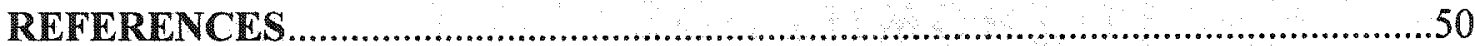

APPENDIX A Raw Data and Calculation for Establishing an Equation

Used to Measure the DLC Thickness by AES ......................52

APPENDIX B Raw Data and Calculation of Verification and Statistical

Analysis of the DLC Thickness Measured by AES..............54

viii 


\section{LIST OF FIGURES}

Figure 1. Schematic cross-section of the thin film structure of a magnetic disk .....4

Figure 2. DC Sputter and its mechanism..............................................................5

Figure 3. ESCA intensities for the $\mathrm{C} 1 \mathrm{~s}$ and $\mathrm{Co} 2 \mathrm{p} 3$ core level signals measured after different carbon deposition times: $0,1,1.5,2,2.5,3$, and 5 s..........7

Figure 4. Comparison of carbon overcoat thicknesses determined by ESCA and XRR $\left[\lambda_{e}=15 \AA\right.$ (open square) or $\lambda_{e}=20 \AA$ (closed circles)] $\ldots \ldots \ldots \ldots \ldots \ldots . . . . . . . .1$

Figure 5. Thickness of the metal oxide layer as a function of the carbon

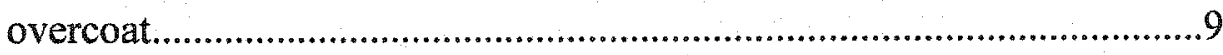

Figure 6. TEM image of a $78 \AA$ thick carbon film...................................................10

Figure 7. Intensities of ESCA cobalt and carbon core peaks ................................10

Figure 8. Comparison of the carbon thickness measured by TEM and ESCA ......11

Figure 9. Schematic diagram of KLL Auger electron generation..........................12

Figure 10. Comparison of Auger electrons escape depth with emission depth of backscattered electrons and $\mathrm{x}$-rays .....................................................13

Figure 11. Schematic diagram of Field Emission Auger Microprobe,

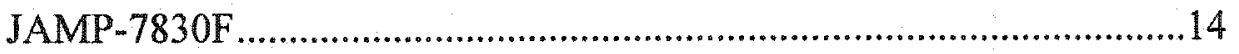

Figure 12. The spectra of $\mathrm{C}$ and $\mathrm{Co}(100 \mathrm{nA}$ and $10 \mathrm{KV})$ with DLC

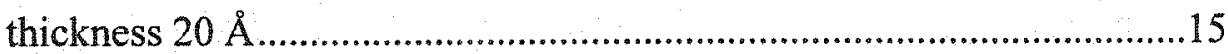

Figure 13. Diagram of the experimental design for establishing a standard equation for measuring the DLC thickness by AES . .20 
Figure 14. Diagram of the experimental design for verification and statistical analysis on the DLC thickness measured by AES ....................................21

Figure 15. The thin films structure of the samples...................................................22

Figure 16. Schematic diagram of the carbon and cobalt electrons emitted from the DLC and the magnetic layer....................................................25

Figure 17. Schematic diagram of the cobalt electrons emitted from the magnetic layer with and without DLC ..................................................26

Figure 18. Schematic diagram of the carbon electrons emitted from thin DLC and infinite DLC .27

Figure 19. The intensities of carbon signal with different DLC thickness measured by AES .31

Figure 20. The intensities of carbon signal measured by AES with the DLC

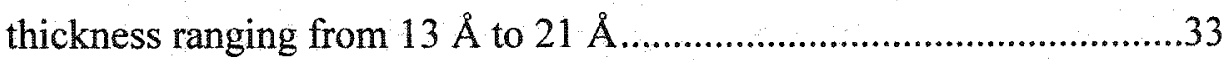

Figure 21. The intensities of the cobalt signal with the different DLC thickness measured by AES...................................................................

Figure 22. AES DLC thickness versus the natural log of the ratio of the intensities of cobalt without and with DLC .35

Figure 23. ESCA DLC thickness versus the natural log of the ratio of the intensities of cobalt signal without and with DLC...................................37

Figure 24. Comparison of DLC thickness determined by ESCA and AES ..............38

Figure 25. Comparative box plot for the DLC thickness measured by ESCA and AES .40 
Figure 26. Comparative box plot of the DLC thickness ( $39 \AA$ ) measured

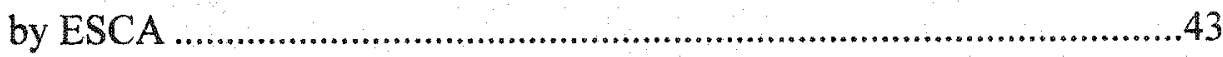

Figure 27. Comparative box plot of the DLC thickness ( $39 \AA)$ measured

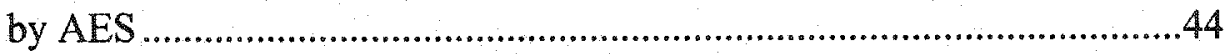

Figure 28. The intensities of cobalt change with the DLC thickness

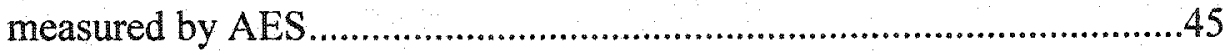

Figure 29. The escape depth variation with the electron take-off angle ...................46 


\section{LIST OF TABLES}

Table I. Comparisons of AES and ESCA $\quad$........................................................16

Table II. Distribution of Samples by Thicknesses.................................................22

Table III. Two-Sample T-Test Results for the DLC Thicknesses Measured

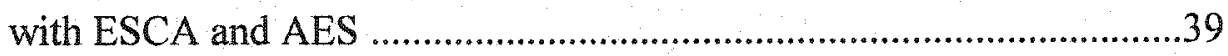

Table IV. Two-Sample T-Test Results for the DLC Thicknesses (39 A)

Measured with ESCA between the Disks................................................41

Table V. Two-Sample T-Test Results for the DLC Thicknesses (39 $\AA$ )

Measured with AES between the Disks......................................................42

Table VI. ESCA DLC Thickness and Intensities of Carbon and Cobalt

Signals Measured by AES ................................................................55

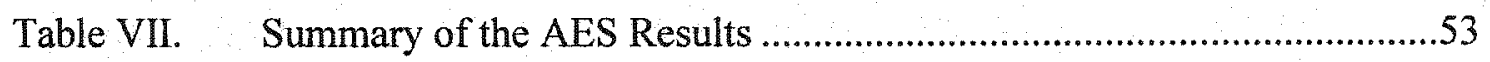

Table VIII. Intensities of Cobalt Signal without the DLC Thickness

Measured by AES ……......................................................................53

Table IX. Calculation of Parameter "a" with the Equation: $d=a_{2} \operatorname{In}\left(I_{C o}{ }^{\circ} / I_{C_{0}}\right) \ldots . .53$

Table X. ESCA DLC Thickness Measurements ........................................................54

Table XI. AES Based DLC Thickness Measurements..............................................55

Table XII. Differences of the DLC Thicknesses Measured by ESCA and AES......55

Table XIII. Variation of the DLC Thicknesses (39 A) between Disks

Measured by ESCA...............................................................................5

Table XIV. Variation of the DLC Thicknesses (39 $\AA$ ) between Disks

Measured by AES 


\section{CHAPTER ONE}

\section{INTRODUCTION}

Increasing the capacity of information storage within magnetic disks has been achieved primarily through mechanical scaling, such as reducing the head to the magnetic recording disk interface (HDI) spacing [1]. The common approach for reducing the HDI spacing is to reduce the thickness of diamond-like carbon (DLC) on the magnetic disk. To protect the magnetic layer from sliding contact and corrosion, the disk is coated with a certain thickness of DLC. Therefore, it is becoming very important for disk manufacturing to accurately measure the DLC thickness.

There are several ways to measure the DLC thickness. These involve the use of Electron Spectroscopy for Chemical Analysis (ESCA) [1,2,3], X-Ray Reflectivity (XRR) [2], or Transmission Electron Microscopy (TEM) [1,3]. Among these, ESCA is most commonly used to measure the DLC thickness in the disk manufacturing industry. A simplified mode of measuring the thickness of carbon using ESCA was proposed by C.M. Mate et al. [2]. They assumed that the electron's inelastic mean free path (IMFP) $[4,5]$ was the same for all materials in the thin film structure and was independent of the electron's kinetic energy. They measured the intensities of the carbon signal that originated from the carbon overlayer and the intensities of the cobalt signal from the magnetic underlayer by using the ESCA core level peaks. The carbon thickness was calculated by using Beer's law of attenuation of underlayer signals by overlying layer through the calibration of XRR. In their study, the ESCA carbon overcoat thickness agreed with the absolute thickness determined by XRR within $20 \%$, with the differences 
presumably arising from the assumptions used to simplify the ESCA analysis. A more general method to measure the DLC thickness with ESCA was discussed by L.J. Huang et al. and $\mathrm{G}$. Barth et al $[1,3]$. In addition to measuring the intensities of carbon and cobalt core level peaks, they proposed a standard equation for measuring the DLC thickness derived for a simple film-substrate model, in which they used a parameter ${ }^{66} \mathrm{a}$ " to estimate the effect of DLC on the inelastic mean free path of carbon and cobalt over the theoretical value. The "a" was calculated from TEM thickness data and carbon and cobalt ESCA signals.

However, ESCA is generally used for a large area thickness measurement (lateral resolution/probe size: $100 \mu \mathrm{m}$ to $2 \mathrm{~mm}$ [6]). In today's disk manufacturing, localized wear and corrosion could cause performance problems, and there is a strong demand for measuring the DLC thickness in an area less than one-micron. Like ESCA, Auger Electron Spectroscopy (AES) is one of the most informative techniques used in surface analysis [7]. Most importantly, AES has the capability to measure micron and sub-micron areas (lateral resolution/probe size: $0.2 \mu \mathrm{m}$ for $\mathrm{LaB}_{6}$ source and $100 \AA$ for Field Emission [6]). Due to the similar analytical capabilities of ESCA and AES and the advantage that AES enables small area analysis, there has been great interest in developing a method to measure the DLC thickness with AES. 


\section{CHAPTER TWO}

\section{LITERATURE REVIEW}

In the following sections, the Beer-Lambert Law is first discussed. This is

followed by a review of the literature regarding DLC, its properties and its application in magnetic recording media. Methods for measuring the thickness of carbon overcoat or DLC on the magnetic disks by ESCA are then discussed. Finally, AES and its analytical capabilities and limitations are discussed and compared with those of ESCA.

\subsection{Beer-Lambert Law}

When light of intensity $\mathbf{I}_{\mathbf{i}}$ passes through a slab of material of thickness $\mathbf{d}$ that contains absorbing species at a concentration $\mathbf{C}$ and an absorption coefficient $\boldsymbol{\alpha}$, the intensity of the transmitted light $\mathbf{I}_{\mathbf{f}}$ falls off exponentially with increasing thickness of the sample due to the absorption behavior of the materials. The Beer-Lambert law [8] is normally written as

$\mathbf{I}_{\mathbf{f}}=\mathbf{I}_{\mathbf{i}} \exp (\boldsymbol{\alpha} \mathbf{C} \mathbf{d})$

Equation 1

or

$\ln \left(\mathbf{I}_{\mathbf{f}} / \mathbf{I}_{\mathbf{i}}\right)=\mathrm{ad}$

Equation 2

where $\mathbf{a}=\boldsymbol{\alpha} \mathbf{C}$. 


\subsection{Diamond-Like Carbon and Its Properties and Application on the Magnetic}

\section{Disks}

Magnetic disks are widely used in disk drives to store most of the data accessible by personal computers and workstations, as well as much of the data being processed by large enterprise servers. The magnetic disk generally consists of a substrate and successive thin film layers over the substrate, including a $\mathrm{Cr}$-containing sublayer, a $\mathrm{Cr}$ crystalline underlayer, a $\mathrm{Co} / \mathrm{Cr} / \mathrm{Pt}$ or $\mathrm{Co} / \mathrm{Ni} / \mathrm{Pt}$ magnetic thin film layer, and carbon overcoat, as shown in Figure 1.

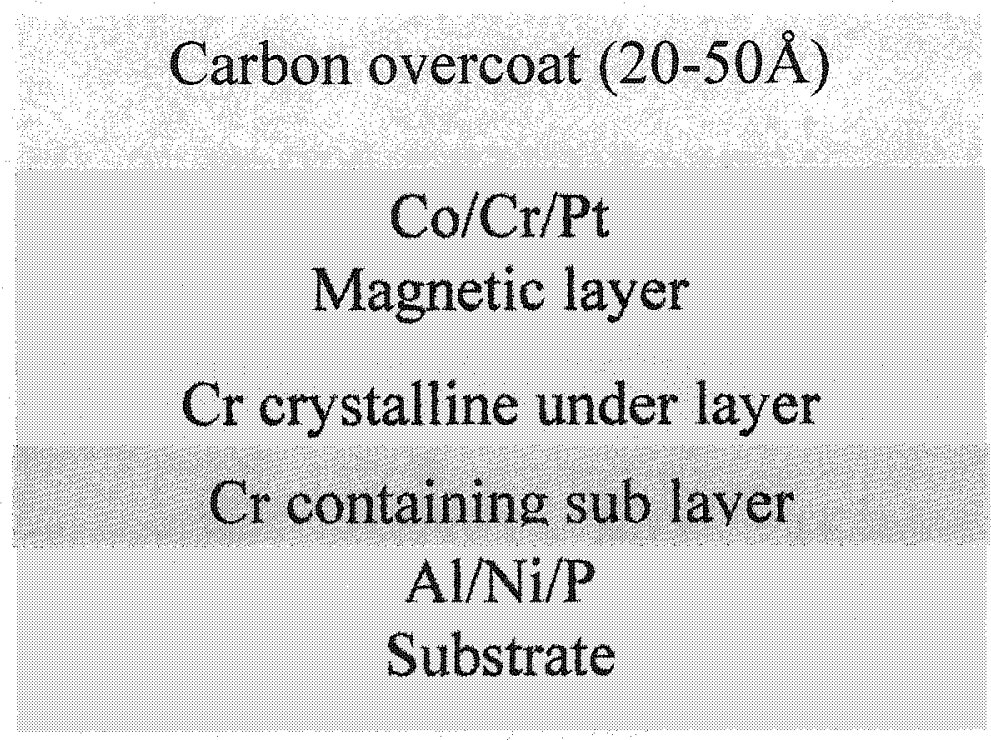

Figure 1. Schematic cross-section of the thin film structure of a magnetic disk 
Generally, the carbon overcoat on the magnetic disk is formed by DC sputtering of carbon onto the magnetic layer, under conditions in which the carbon forms a predominantly diamond-like structure that is $20-50 \AA$ thick. A schematic of the DC sputtering process [9] is shown in Figure 2. Negative voltages $(2-3 \mathrm{kV})$ are applied to the carbon target with argon gas in the chamber. As the accelerated electrons from an electron gun knock off the electrons of argon atoms, the argon atoms are ionized positively and accelerated toward the negative charged carbon target. As a result, carbon atoms are knocked off, land on the disk, and stick to form the thin film.

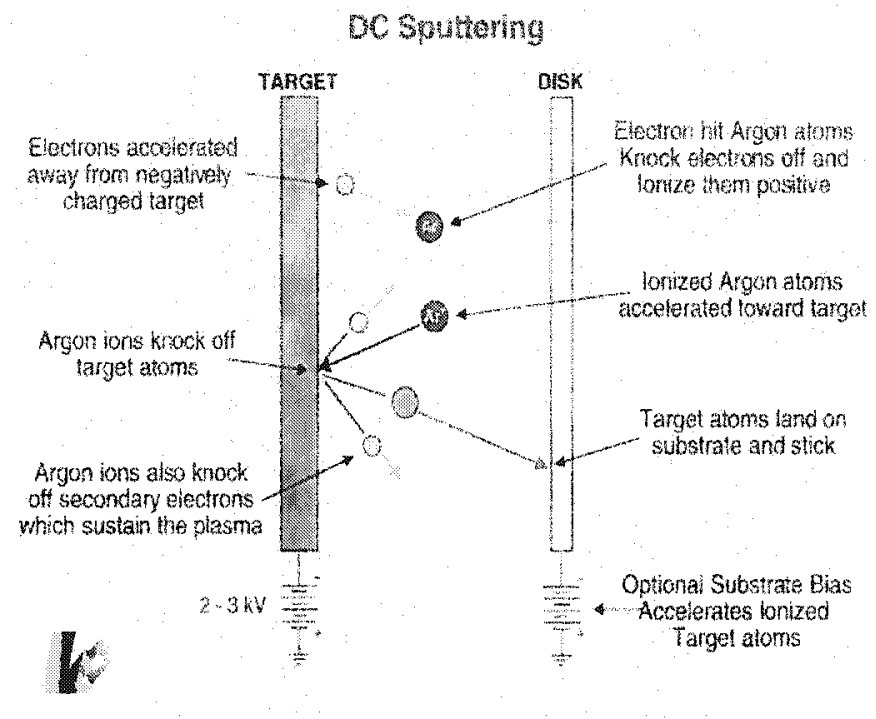

Figure 2. DC Sputter and its mechanism [9]

Diamond-like carbon is a useful material because it has extreme hardness, chemical inertness, high electrical resistivity, high dielectric strength, high thermal 
conductivity, and optical transparency. Because of these properties, diamond-like carbon is used on magnetic disks to protect the magnetic layer from sliding contact and corrosion.

\subsection{Thickness Measurement of the Carbon Overcoat by Correlating ESCA with XRR Results}

C.M. Mate et al. [2] proposed a simplified method to measure the thickness of carbon using ESCA. They assumed that the inelastic mean free path (IMFP) of electrons was the same for all materials in the thin film structure and independent of the electron's kinetic energy. They measured the intensities of the carbon signal that originated from the carbon overlayer and the cobalt signal from the magnetic underlayer, as shown in Figure

3. The carbon thickness was calculated by using Beer's law of attenuation of underlayer signals by the overlayer with the results being correlated with XRR results [2],

$$
\mathbf{I}_{\mathbf{C}}=\mathbf{I}_{\mathbf{C o}} \exp \left[\mathbf{d} / \lambda_{\mathrm{e}} \sin (\boldsymbol{\theta})\right] \quad \text { Equation } 3
$$

where $I_{C}$ was the intensity of the $\mathrm{C}$ (1s) signal originating from carbon in the carbon overcoat, $\mathbf{I}_{\mathbf{C o}}$ was the intensity of $\mathrm{Co}(2 \mathrm{p} 3)$ signal from cobalt in the magnetic layer, $\mathbf{d}$ was the thickness of the carbon overcoat, $\lambda_{\varepsilon}$ was the electron inelastic mean free path, and $\theta$ was the electron take off angle. 

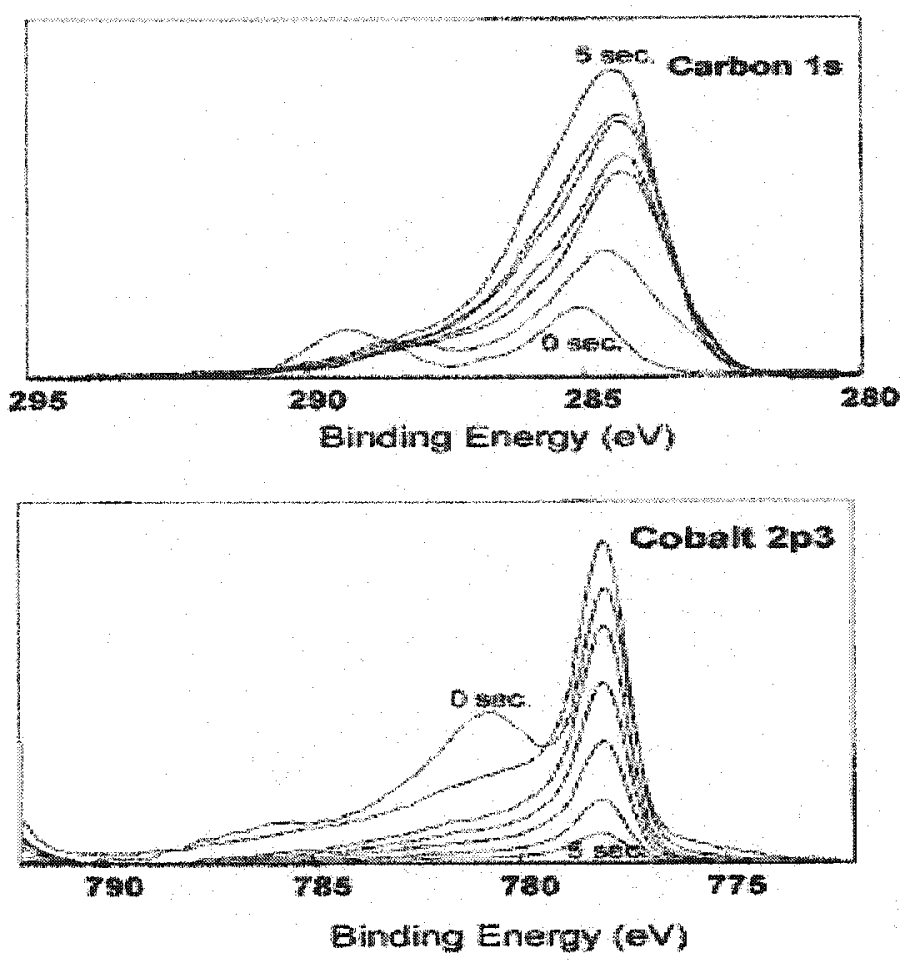

Figure 3. ESCA intensities for the $\mathrm{C} 1 \mathrm{~s}$ and $\mathrm{Co} 2 \mathrm{p}^{3}$ core level signals measured after different carbon deposition times of $0,1,1.5,2,2.5,3$, and $5 \mathrm{~s}[2]$

Figure 4 contains a comparison of the carbon overcoat thickness measured by ESCA and XRR when $\lambda_{\mathrm{e}}$ was equal to $15 \AA$ and $20 \AA$. The ESCA carbon overcoat thickness agreed with the absolute thickness determined by XRR within 20\%, with the differences presumably arising from the assumptions used to simplify the ESCA analysis. The results indicate that ESCA, if calibrated by XRR, could be used to measure the carbon overcoat thickness. 


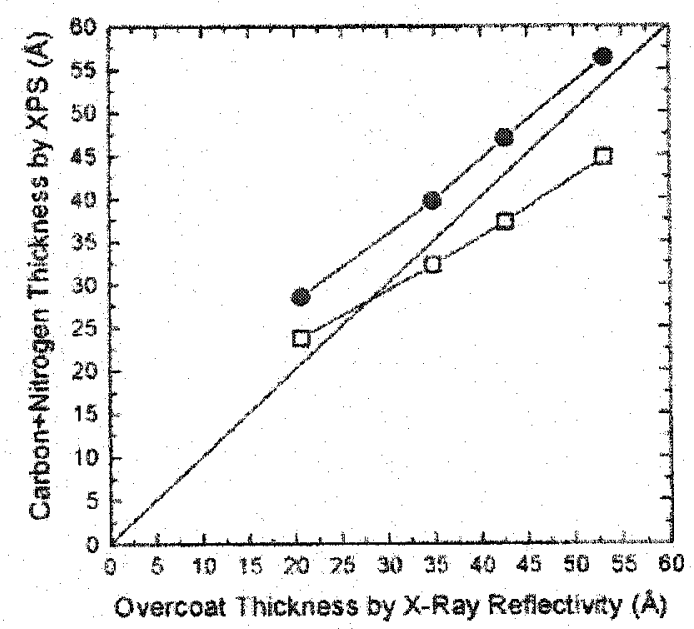

Figure 4. Comparison of carbon overcoat thicknesses determined by ESCA and XRR [2] $\left[\lambda_{\mathrm{e}}=15 \AA\right.$ (open square) or $\lambda_{\mathrm{e}}=20 \AA$ (closed circles) $]$

The authors suggested that the thickness of the metal oxide layers could be determined by the intensities of the $\operatorname{Co} 2 \mathrm{p}^{3}$ core level peaks. The formation of a metal oxide layer indicated that the carbon overcoat was not completely covering the magnetic layer, as oxygen from air was able to react with the metal atoms in the underlying magnetic layers.

The thickness of the metal oxide layer as a function of the carbon thickness is shown in Figure 5. When the carbon overcoat was thinner than $20 \AA$, the carbon overcoat was not continuous, and as a result metal oxide peaks were readily apparent in the ESCA spectra. The authors stated that this result has been verified by other studies, although no references were provided. 


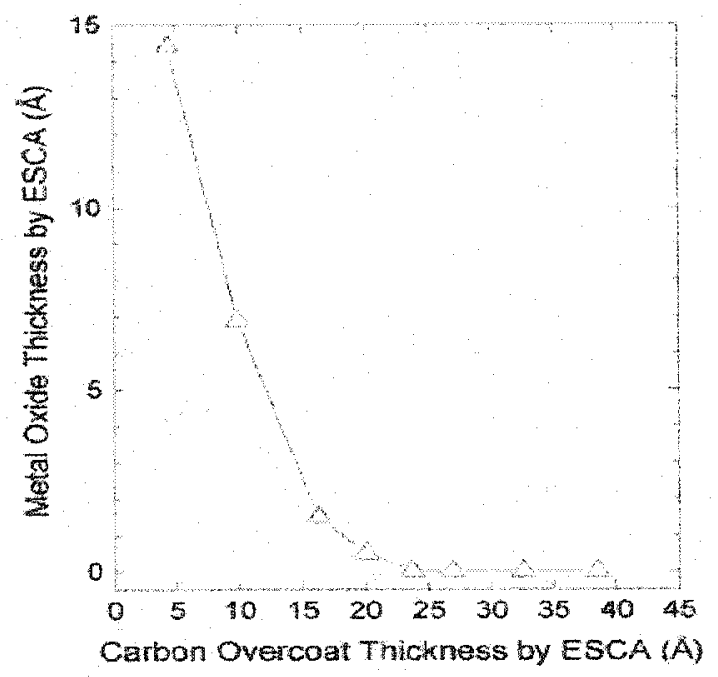

Figure 5. Thickness of the metal oxide layer as a function of the carbon overcoat [2]

\subsection{Carbon Thickness Measured by ESCA and TEM}

The general method used to measure the DLC thickness with ESCA was discussed by L.J. Huang et al. [1] and G. Barth et al [3]. In addition to measuring the intensities of the carbon and cobalt core peaks, they proposed a standard equation for measuring the DLC thickness derived for a simple film-substrate model, in which they used a parameter "a" to estimate the effect of the DLC on the inelastic mean free path of carbon $1 \mathrm{~s}$ and cobalt $2 \mathrm{p} 3$ electrons with respect to the theoretical values. The parameter "a" was derived from TEM thickness data, as shown in Figure 6, and the carbon and cobalt ESCA signals, as shown in Figure 7. The carbon thickness was calculated by $[1,3]$ :

$\mathbf{d}=\boldsymbol{\lambda} \cos (\boldsymbol{\theta}) \ln \left[1+\mathbf{a}\left(\mathbf{I}_{\mathbf{C o}} / \mathbf{I}_{\mathbf{C}}\right)\right] \quad$ Equation 4 
where $\mathbf{I}_{\mathbf{C}}$ was the intensity of the $\mathrm{C} 1 \mathrm{~s}$ signal originating from carbon in the carbon overcoat. $\mathbf{I}_{\mathrm{Co}}$ was the intensity of the $\mathrm{Co} 2 \mathrm{p}^{3}$ signal from cobalt in the magnetic layer. $\mathrm{d}$ was the thickness of carbon overcoat. $\lambda$ was the electron inelastic mean free path. $\theta$ was the electron take-off angle.

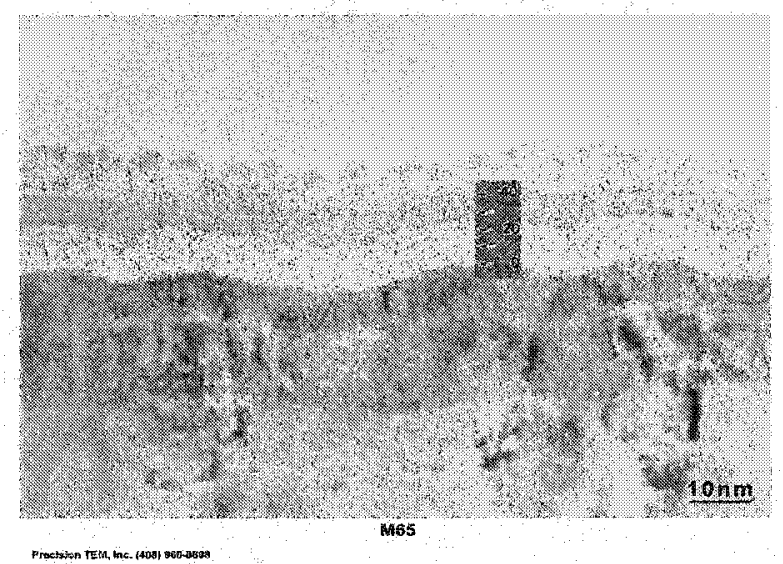

Figure 6. TEM image of a $78 \AA$ thick carbon film [3]

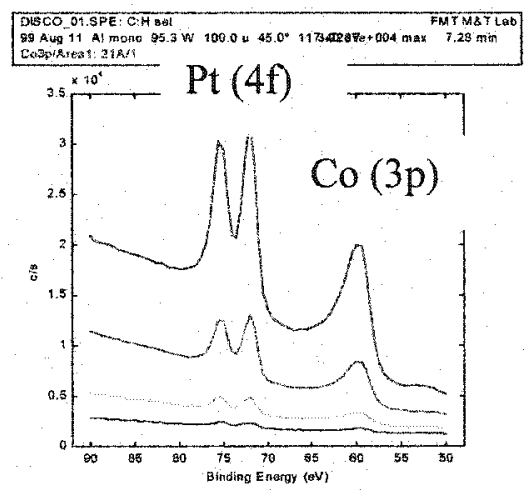

Co signal

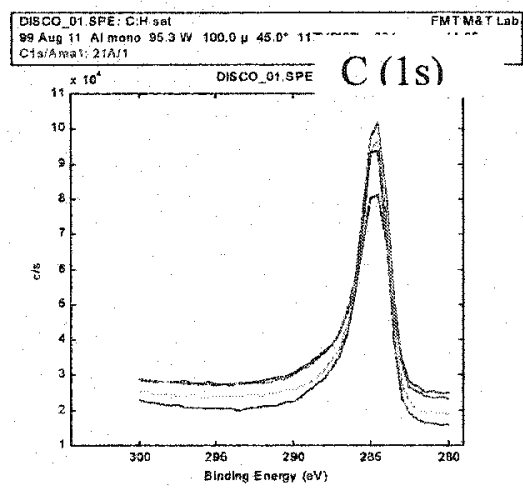

C signal

Carbon thickness: red: $35 \AA$, blue: $57 \AA$, maten: $76 \AA$, violet: $100 \AA$

Figure 7. Intensities of ESCA cobalt and carbon core peaks [3] 
The value of "a" determined from TEM and the intensities of photoelectrons of carbon and cobalt (the cobalt concentration in the magnetic layer was $60-70$ atom\%) was 0.39. The authors assumed that the IMFP of cobalt $2 p^{3}$ electrons was equal to the IMFP of carbon 1s electrons $(25 \AA)$. When the electron take-off angle was $45^{\circ}$, the carbon thickness could be calculated with Equation 4. A comparison of the carbon overcoat thickness measured by ESCA and TEM is shown in Figure 8. Data fitting indicated that there was a good correlation for carbon thickness measured by ESCA and TEM.

Therefore, when ESCA was calibrated by TEM, it could be used to measure the DLC thickness.

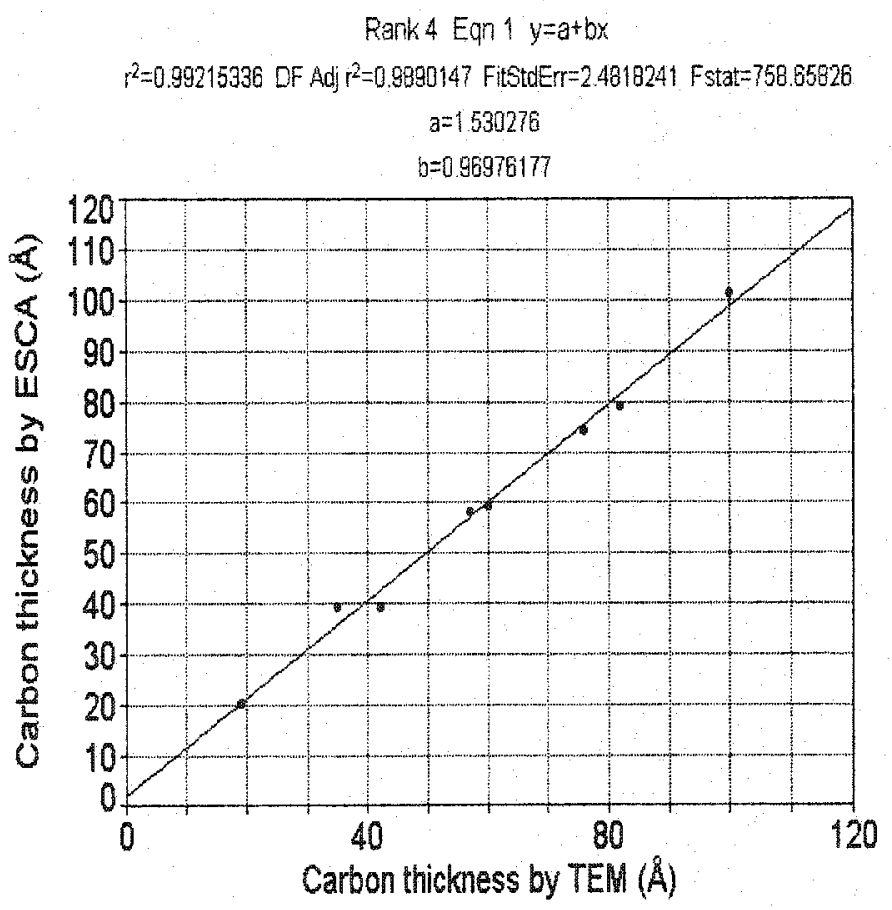

Figure 8. Comparison of the carbon thickness measured by TEM and ESCA [3] 


\subsection{AES and Its Comparison with ESCA}

Auger electrons were discovered by Pierre Auger in France in 1925. The measurement of Auger electrons was developed into a surface analysis method in 1968. When a sufficiently energetic particle or photon strikes an atom, a vacancy is formed in its inner electron shell. This atom is unstable, and de-excitation occurs immediately, resulting in the emission of Auger electrons or an x-ray, as shown in Figure 9. Except for hydrogen and helium, all the elements in the periodic table can emit Auger electrons and be recognized by the Auger spectra. The energy of Auger electrons measured by most AES instruments usually ranges from $10-2500 \mathrm{eV}[6,7,10,11]$, and their mean free paths in a condensed phase, usually a solid, are $0.4-4 \mathrm{~nm}[6,7,10,11]$. Consequently, Auger electrons can be examined only when they are emitted from the surface.

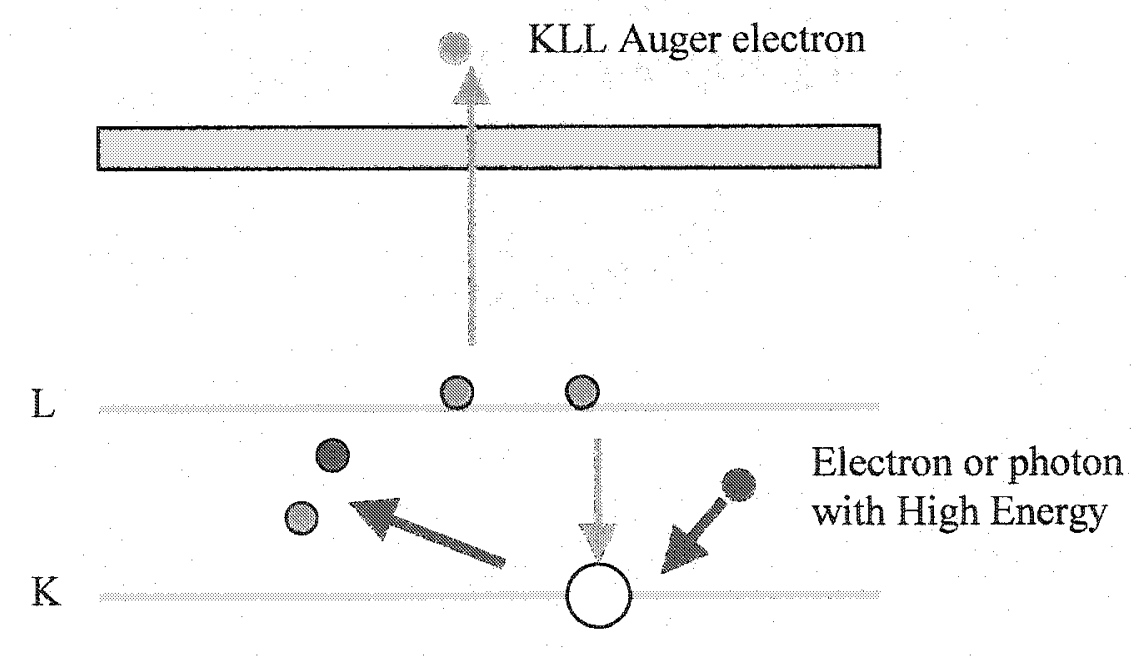

Figure 9. Schematic diagram of KLL Auger electron generation 
The electron escape depth is the average depth from which electrons escape from the surface of solid without losing energy [11]. If $\lambda$ is the inelastic mean free path of the electrons, then the escape depth of electrons is a distance $3 \lambda$ within the solid, where $95 \%$ of the signal intensity is obtained [12]. The escape depth of Auger electrons is small as compared with $\mathrm{x}$-ray emission and backscattered electrons [6], as shown in Figure 10.

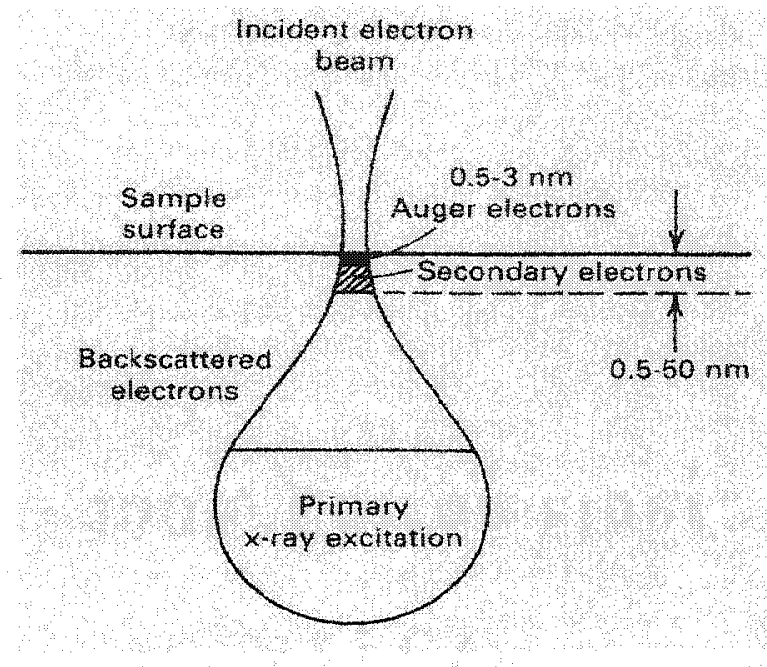

Figure 10. Comparison of Auger electrons escape depth with emission depth of backscattered electrons and $\mathrm{x}$-rays [6]

The combination of a field emission based electron gun, high performance electron optical system, well designed stage, and high-resolution electron energy analyzer has made AES a powerful surface analytical tool. Figure 11 is a schematic diagram of the Field Emission Auger Microprobe (JAMP-7830F) that was used for the study of the DLC thicknesses. 


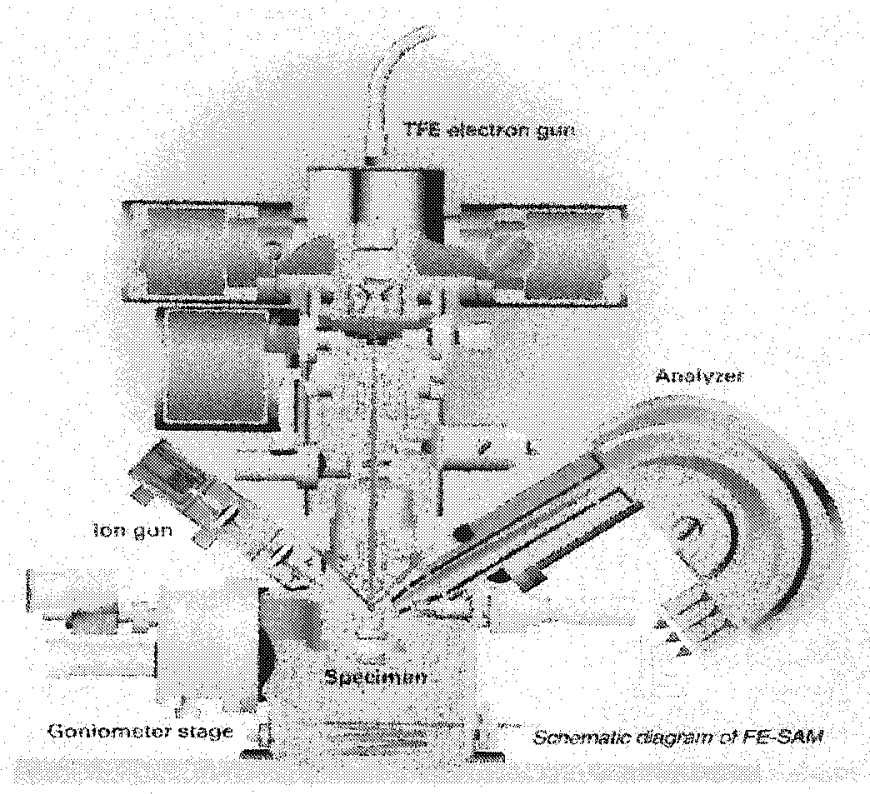

Figure 11. Schematic diagram of Field Emission Auger Microprobe, JAMP-7830F (JEOL)

The general uses of AES are (1) compositional analysis, (2) depth compositional profiling, (3) high lateral resolution surface chemical analysis, (4) grain boundary and other interface analyses, and (5) phase identification. Among them, the most important capability for this study is the ability of compositional analysis. Figure 12 includes the spectra of carbon and cobalt with a DLC thickness of $20 \AA$ [13]. Quantitative analysis of the Auger spectra provides the intensities of carbon and cobalt signals. 


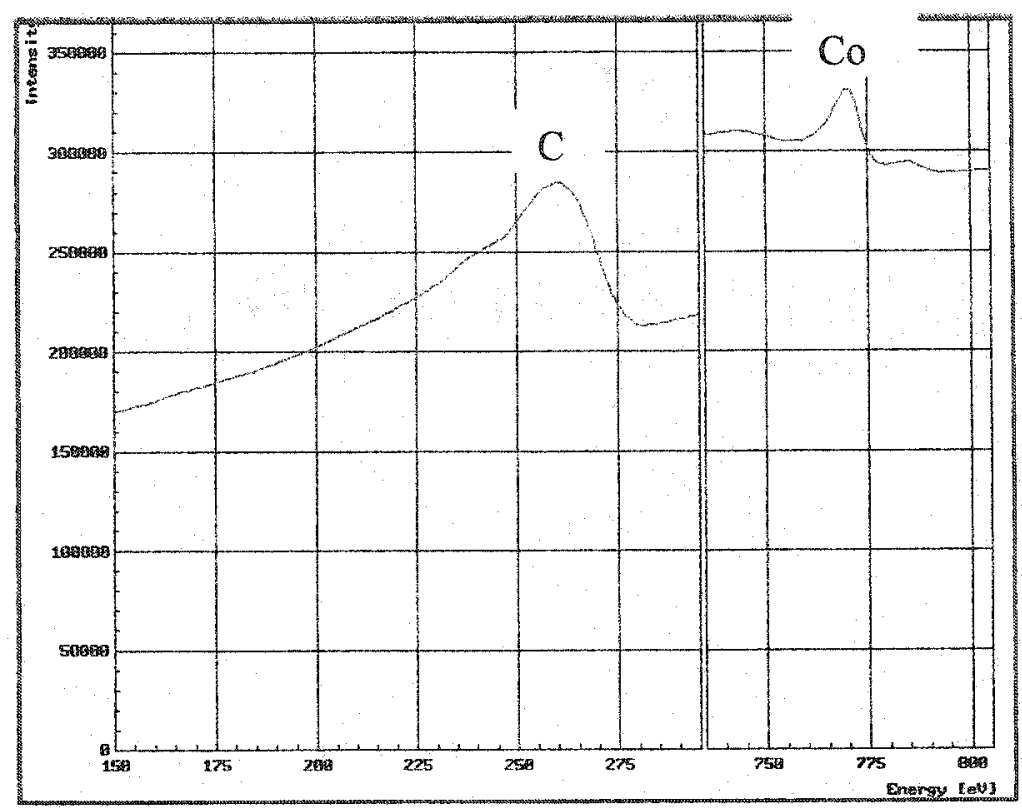

Figure 12 . The spectra of carbon and cobalt (100A and $10 \mathrm{KV})$ with DLC thickness $20 \AA$ [13]

Both AES and ESCA yield precise measurements of the number of emitted secondary electrons as a function of kinetic energy. A comparison of AES and ESCA techniques as discussed by Charles Evans \& Associates is tabulated in Table I [14]. The significant difference between ESCA and AES is the probe size. ESCA has a lateral resolution/probe size of $10 \mu \mathrm{m}$ to $2 \mathrm{~mm}$ [6] and is generally used for a large area analysis. On the other hand, AES has a much smaller lateral resolution/probe size of $0.2 \mu \mathrm{m}$ for a $\mathrm{LaB}_{6}$ source and $100 \AA$ for a Field Emission source [6] and has the analytical capability to analyze an area less than one-micron. Therefore, it is a significant advantage to use AES for surface analysis. However, there are some limitations $[6,7,10,11]$ in the 
application of AES, including its insensitivity to hydrogen and helium and its relatively low detection sensitivity for all elements. The quantitative detection sensitivity range for most elements is from 0.1 to 1 at.\%. Another limitation involves electron beam artifacts, uncontrollable charging of non-conducting materials, and damaging the surface of specimens. Spectral peak overlap is another problem in AES analysis. Due to the need for ultra high vacuum conditions, it is not possible to measure samples that have high vapor pressures. Furthermore, when using published elemental sensitivity factors, the accuracy of quantitative analysis is limited to roughly $30 \%$ of the measured value.

Table I Comparison of AES and ESCA [14]

\begin{tabular}{|c|c|c|c|c|c|c|}
\hline $\begin{array}{l}\text { Analytical } \\
\text { Technique }\end{array}$ & $\begin{array}{l}\text { Typical } \\
\text { Application }\end{array}$ & $\begin{array}{l}\text { Signal } \\
\text { Detected }\end{array}$ & $\begin{array}{l}\text { Elements } \\
\text { Detected }\end{array}$ & $\begin{array}{l}\text { Detection } \\
\text { Limits }\end{array}$ & $\begin{array}{l}\text { Depth } \\
\text { Resolutio } \\
\mathrm{n}\end{array}$ & \begin{tabular}{|l|} 
Lateral \\
Resolution \\
/Probe Size \\
\end{tabular} \\
\hline Auger & $\begin{array}{l}\text { Surface } \\
\text { analysis and } \\
\text { high depth } \\
\text { resolution } \\
\text { profiling }\end{array}$ & $\begin{array}{l}\text { Auger } \\
\text { electrons } \\
\text { from near } \\
\text { surface } \\
\text { atoms }\end{array}$ & $\mathrm{Li}-\mathrm{U}$ & $\begin{array}{l}0.1-1 \\
\text { at } \%\end{array}$ & $\begin{array}{l}20-200 \AA \\
\text { (Profiling } \\
\text { mode) } \\
30 \AA \\
\text { (Surface } \\
\text { analysis) } \\
\end{array}$ & \begin{tabular}{|l|}
$0.2 \mu \mathrm{m}$ \\
$\left(\mathrm{LaB}_{6}\right.$ \\
source $) 100$ \\
$\AA$ \\
(Field \\
Emission) \\
\end{tabular} \\
\hline ESCA/XPS & $\begin{array}{l}\text { Surface } \\
\text { analysis of } \\
\text { organic and } \\
\text { inorganic } \\
\text { materials, } \\
\text { depth } \\
\text { profiling } \\
\end{array}$ & $\begin{array}{l}\text { Photoele } \\
\text { ctrons } \\
\text { from near } \\
\text { surface } \\
\text { atoms }\end{array}$ & $\mathrm{Li}-\mathrm{U}$ & $\begin{array}{l}0.01-1 \\
\text { at } \%\end{array}$ & $\begin{array}{l}20-200 \AA \\
\text { (Profiling } \\
\text { mode) } \\
10-100 \AA \\
\text { (Surface } \\
\text { analysis) }\end{array}$ & $\begin{array}{l}10 \mu \mathrm{m}- \\
2 \mathrm{~mm}\end{array}$ \\
\hline
\end{tabular}

\subsection{Summary}

The DLC film on a magnetic disk plays a very important role in increasing the density of recording of magnetic disks and protecting the magnetic layers from sliding 
contact and corrosion. One of the methods used to measure the thickness of DLC is based on Electron Spectroscopy For Chemical Analysis (ESCA), which is used to measure the DLC thickness over a relatively large area (lateral resolution/probe size: $100 \mu \mathrm{m}$ to $2 \mathrm{~mm}$ [6]). Like ESCA, AES also has surface analysis capabilities for detecting electrons from near surface atoms. When the overlying DLC and underlying magnetic layer are irradiated with a sufficiently energetic electron beam, the Auger electrons from carbon in the DLC, and cobalt in the underlying magnetic layer, can be excited. The intensities of the Auger signals from carbon and cobalt can be measured quantitatively. These intensities fall off exponentially as the thickness of the DLC increases, which is predicted by Beer's law. AES signals, however, can be used for measuring the DLC thickness in an area less than one-micron (lateral resolution/probe size: $0.2 \mu \mathrm{m}$ for $\mathrm{LaB}_{6}$ source and 100 $\AA$ for a Field Emission source [6]). Thus the measurement of emitted Auger electrons of carbon and cobalt affords an indirect measurement of the DLC thickness in an area less than one micron. 


\section{CHAPTER THREE \\ PROJECT HYPOTHESIS AND OBJECTIVES}

\subsection{Hypothesis}

Electron Spectroscopy for Chemical Analysis (ESCA) is widely used to measure the DLC thickness in the magnetic recording disk manufacturing industry. Auger Electron Spectroscopy (AES) has surface analysis capability similar to ESCA. Since Beer's law holds true for both techniques, and AES can be used to analyze a specimen in an area less than one-micron, AES can be used for the thickness measurement of the diamond-like carbon (DLC) in a micron-sized area.

\subsection{Objectives}

The primary objective of this study was to establish a method to measure the DLC thickness by AES, to verify the DLC thickness measured by AES with ESCA, and to determine the statistical similarity, or differences, between DLC thicknesses measured with AES and ESCA.

Another objective of this study was to determine the maximum DLC thickness that can be measured by AES. 


\section{CHAPTER FOUR}

\section{EXPERIMENTAL DESIGN AND APPARATUS}

\subsection{Experimental Design}

The method to measure the DLC thickness by AES was developed by constructing a working curve that used the thickness of DLC measured by ESCA and the intensities of the carbon and cobalt signals measured by AES. This approach generated a calibration parameter "a". The equation for DLC thickness calculation, as applied to AES, was based on the Beer-Lambert law and the parameter "a".

Figure 13 contains a diagram of the experimental design that was used to establish a standard equation for calculating the DLC thickness as measured by AES. This design included 6 basic steps: (1) prepare eight disks with DLC thickness $20 \AA, 25 \AA, 30 \AA, 35 \AA$, $40 \AA, 45 \AA, 50 \AA$ and $55 \AA$, (2) use ESCA to measure the DLC thickness (three points for each sample), (3) use AES to measure the intensities of carbon and cobalt signals (ten points for each sample), (4) construct a working curve to get the calibration parameter "a", (5) establish an equation for the calculation of DLC thickness measured by AES, and (6) calculate the maximum measurable DLC thickness by using the IMFP of cobalt or intensities of cobalt Auger signal.

In Figure 14, the experimental approach for verifying the DLC thickness and for the statistical analysis on the DLC thickness measured by AES is shown. This design included 5 basic steps: (1) prepare 4 groups of disks with expected DLC thickness $20 \AA$, $30 \AA, 40 \AA$, and $50 \AA$ ( 4 disks for each group and total 16 disks), (2) use AES to measure the intensities of carbon and cobalt signals (ten points for each disk) and calculate the 
DLC thickness with the established AES method, (3) use ESCA to verify the DLC thickness measured by AES, (4) statistically analyze the differences of DLC thickness measured with ESCA and AES, and (5) statistically analyze the variability of the DLC thickness measurements between the disks. The group with $40 \AA$ DLC thickness was selected to determine the differences in the thicknesses of the various DLC coatings.

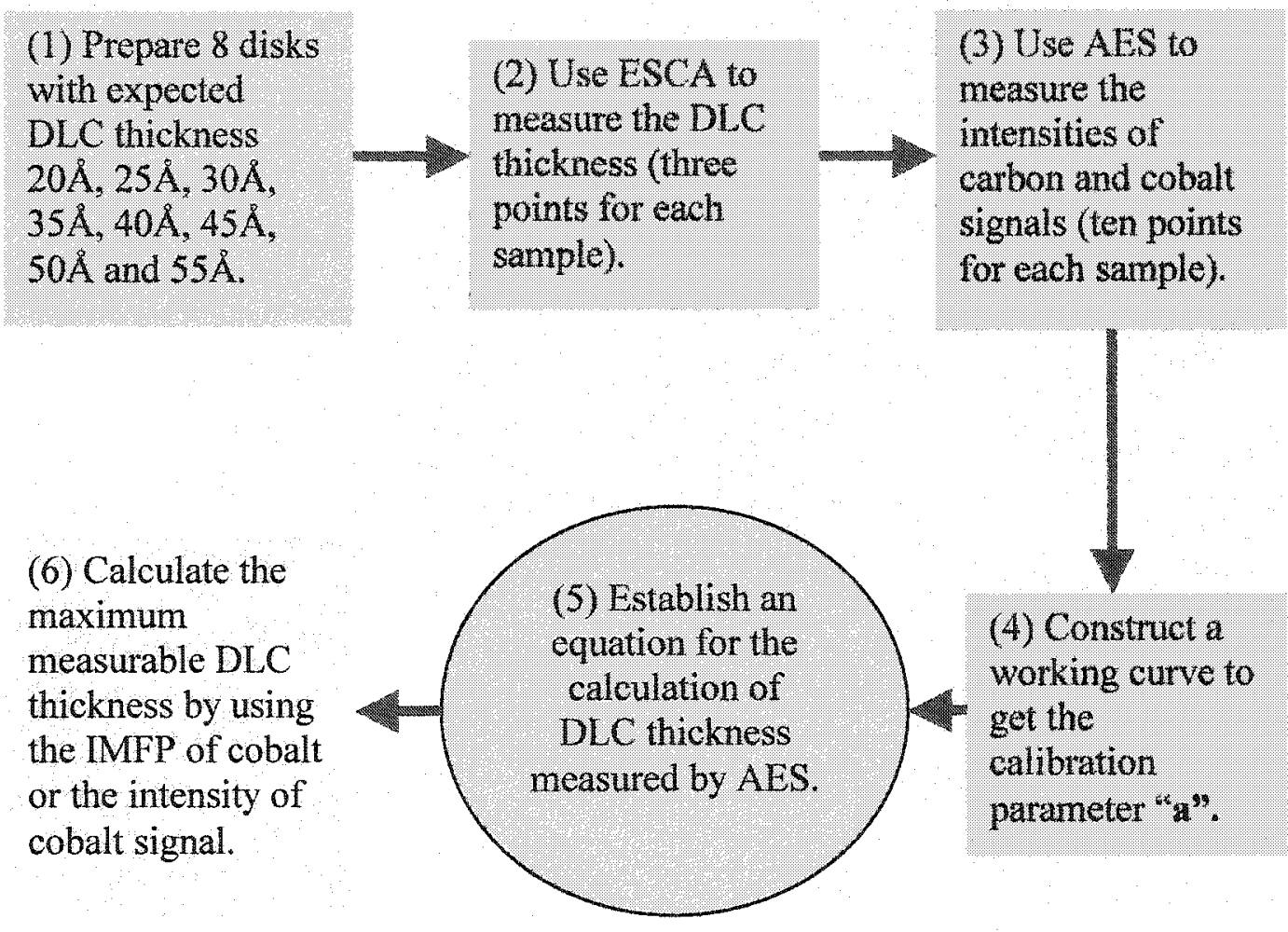

Figure 13. Diagram of the experimental design for establishing a standard equation for measuring the DLC thickness by AES 
(1) Prepare 4 groups disks with expected DLC thickness $20 \AA$, $30 \AA, 40 \AA$, and $50 \AA$ (4 disks for each group and total 16 disks).
(2) Use AES to measure the intensities of carbon and cobalt signals (ten points for each disk) and calculate the DLC thickness with the established AES method.
(3) Use ESCA to verify the DLC thickness measured by AES.

(4) Statistically analyze the differences of DLC thickness measured with ESCA and AES. (5) Statistically analyze the variability of the DLC thickness measurements

Figure 14. Diagram of the experimental design for verification and statistical analysis on the DLC thickness measured by AES

\subsection{Sample Preparation}

The disks with different DLC thickness were prepared in the same way as regular magnetic disks, including the aluminum alloy base and electroless plated nickelphosphorus, texture, a $\mathrm{Cr}$ containing sublayer, a $\mathrm{Cr}$ crystalline underlayer, a $\mathrm{Co} / \mathrm{Cr} / \mathrm{Pt}$ magnetic thin film layer (60-70 atom\% of cobalt), and a DLC layer. This is shown in Figure 15. The DLC was formed by using a Multiple-Disk-Process (MDP) sputter deposition machine to produce different thicknesses by varying the sputtering time, with a predominantly diamond-like structure generated by controlling the sputtering conditions. There were three sets of samples, as shown in Table II. One was a group of disks with DLC thicknesses ranging from $20 \AA$ to $55 \AA$ in increments of $5 \AA$. Another 
was a group of disks with expected DLC thicknesses of $20 \AA, 30 \AA, 40 \AA$, and $50 \AA$, with 4 disks for each DLC thickness. The third was a group of disks with expected DLC thicknesses of $13 \AA, 16 \AA, 19 \AA$, and $21 \AA$. Hydrogen and nitrogen were added during DLC sputtering to increase bonding between the carbon overcoat and magnetic layer and increase the hardness of the DLC. The samples were used without lubricant.

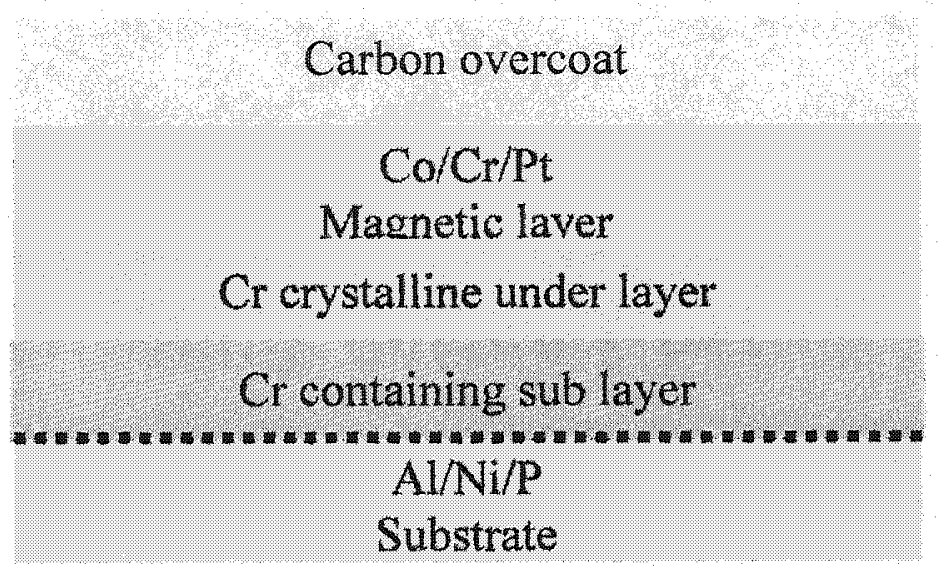

Figure 15. The thin films structure of the samples

Table II. Distribution of Samples by Thicknesses

\begin{tabular}{|c|c|c|c|c|c|c|c|c|}
\hline \multirow{2}{*}{ Group 1 } & $20 \AA$ & $25 \AA$ & $30 \AA$ & $35 \AA$ & $40 \AA$ & $45 \AA$ & $50 \AA$ & $55 \AA$ \\
\cline { 2 - 7 } & 1 disk & 1 disk & 1 disk & 1 disk & 1 disk & 1 disk & 1 disk & 1 disk \\
\hline \multirow{2}{*}{ Group 2 } & $20 \AA$ & $30 \AA$ & $40 \AA$ & $50 \AA$ \\
\cline { 2 - 6 } & 4 disks & 4 disks & 4 disks & 4 disks \\
\hline \multirow{2}{*}{ Group 3 } & $13 \AA$ & $16 \AA$ & $19 \AA$ & $21 \AA$ \\
\cline { 2 - 6 } & 1 disk & 1 disk & 1 disk & 1 disk \\
\hline
\end{tabular}




\subsection{Electron Spectroscopy for Chemical Analysis (ESCA)}

The DLC thicknesses were measured with a Physical Electronics Quantum 2000 Scanning Electron Spectrometer using a monochromatic Al Ka X-ray, a spot size of $300 \mu \mathrm{m}$, pass energy of $25 \mathrm{eV}$, and a scan size of $1 \mathrm{~mm} \times 0.3 \mathrm{~mm}$. The DLC thickness at three different locations for each sample were measured for establishing the standard equation for AES DLC thickness calculation and verifying DLC thickness measured with AES.

\subsection{Auger Electron Spectroscopy (AES)}

In this study, the intensities of carbon and cobalt signals were taken by using the Field Emission Auger Microprobe, JAMP-7830F, with an electron beam energy of $10 \mathrm{keV}$, probe current of $10 \mathrm{nA}$, a probe diameter of $25 \mu \mathrm{m}$, a scan size of $0.1 \mathrm{~mm} \times 0.1$ $\mathrm{mm}$, analyzer resolution of $0.35 \%$, and an electron takeoff angle of $65^{\circ}$ (tilt angle $30^{\circ}$ ). Ten points on each disk were measured. Furthermore, the intensities of the cobalt Auger signal without a DLC coating were measured after removing the DLC with an ionetching gun. The etching rate was $4.2 \mathrm{~nm} / \mathrm{min}$. The etching time was varied from 60 seconds to 150 seconds depending on the DLC thickness.

\subsection{Calculation of DLC Thickness}

When the overlying DLC and underlying magnetic layer were radiated with a sufficiently energetic electron beam, the Auger electrons from carbon in DLC and cobalt in the magnetic layer could be excited. According to the Beer-Lambert Law [8], the intensities of Auger electrons from carbon and cobalt fell off exponentially with the increased thickness of DLC. The application of Beer's law for DLC thickness 
measurement can be applied to three different systems [15,16,17]: (1) carbon and cobalt signals from the DLC and the magnetic layer, (2) cobalt signals from the magnetic layer only, (3) carbon signals from the DLC film only.

\subsubsection{Carbon and Cobalt Signals from the DLC and Magnetic Layer}

DLC thickness measurement involved detecting the emission of carbon and cobalt Auger electrons from the overlying DLC and underlying magnetic layer when excited by a sufficiently energetic electron beam, as shown in Figure 16. According to Beer's law, the DLC thickness could be calculated by $[1,3]$ :

$d=\lambda_{C} \sin (\theta) \ln \left[1+\mathbf{a}_{1}\left(\mathbf{I}_{C} / \mathbf{I}_{\mathbf{C O}}\right)\right] \quad$ Equation 5

where $\lambda_{C}$ was the inelastic mean free path of carbon electrons [4]. $\mathbf{I}_{\mathbf{C}}$ and $\mathbf{I}_{\mathbf{C o}}$ were the intensities of the carbon and cobalt Auger electrons emitted from the DLC and the magnetic layer. $\theta$ was the electron take-off angle. $\mathbf{a}_{1}$ was the calibration parameter for the DLC thickness measurement based on the intensities of carbon and cobalt signals. It was determined experimentally by constructing a working curve using known DLC thicknesses (measured by ESCA) and the intensities of the carbon and cobalt signals measured by AES. 


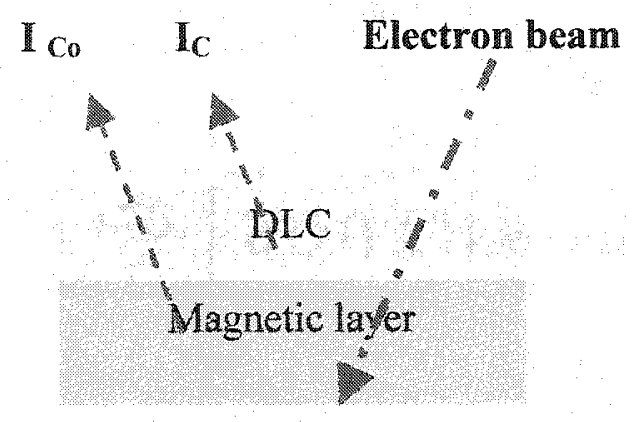

Figure 16. Schematic diagram of the carbon and cobalt electrons emitted from the DLC and magnetic layer

\subsubsection{Cobalt Signals from the Magnetic Layer Only}

The DLC thickness measured by Auger emission from cobalt in the magnetic layer was illustrated schematically in Figure 17. An electron beam irradiated upon the DLC film and magnetic layer, exciting Auger electrons of cobalt from the magnetic layer. Emitted Auger electrons of cobalt that passed through the DLC layer and came out from the surface had an intensity of $\mathbf{I}_{\mathrm{Co}_{0}}$ that depended on the DLC thickness $\mathbf{d}$. If $\mathbf{I}_{\mathbf{C o}}{ }^{\circ}$ was the intensity of cobalt electrons emitted from the magnetic layer without DLC, then following Beer's law, the DLC thickness could be calculated by $[11,15]$ :

$$
\mathbf{I}_{C_{0}}=\mathbb{I}_{C_{0}}{ }^{0} \exp \left[-d / \lambda_{C} \sin (\theta)\right]
$$

Equation 6

or

$$
d=a_{2} \ln \left(\mathbb{I}_{\mathbf{C}_{0}}{ }^{0} / \mathbf{I}_{\mathbf{C O}_{0}}\right)
$$

Equation 7 
where $\mathbf{a}_{2}$ was the calibration parameter for DLC thickness measurement using the intensity of cobalt signal only. It was determined experimentally by constructing a working curve using known DLC thickness (measured by ESCA) and the intensities of the cobalt signal with and without DLC as measured by AES.

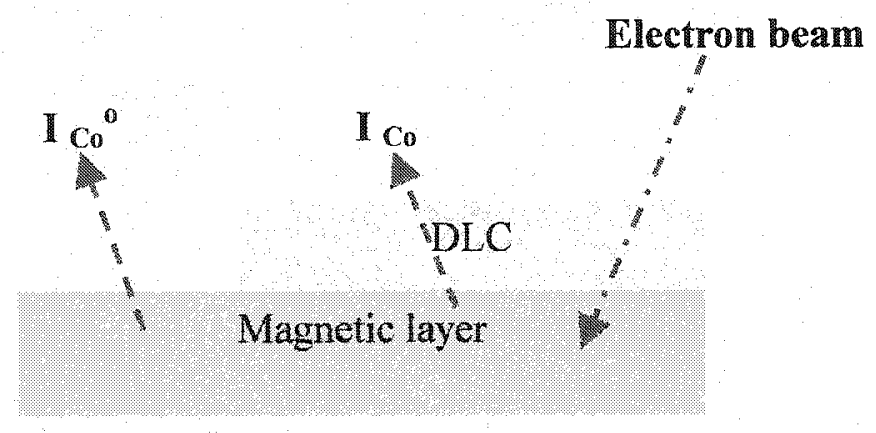

Figure 17. Schematic diagram of the cobalt electrons emitted from the magnetic layer with and without DLC

\subsubsection{Carbon Signals from the DLC Film Only}

Another method to measure the DLC thickness involved only the carbon signal from the DLC film, as shown in Figure 18. Carbon was present in the DLC film but absent in the magnetic layer. Theoretically, the intensity of the carbon signal would increase with increased DLC thickness. However, when the critical DLC thickness was reached, there was no further increase in the intensity of the carbon signal. When DLC thickness was less than the critical thickness, according to Beer's law, the DLC thickness could be calculated by $[11,15]$ : 
$\mathbb{I}_{C}=\mathbb{I}_{C}^{\infty}\left[1-\exp \left(-d / \lambda_{C} \sin (\theta)\right]\right.$

or

$\mathbf{d}=\mathbf{a}_{3} \ln \left[\mathbf{I}_{\mathbf{C}}^{\infty} /\left(\mathbf{I}_{\mathbf{C}}^{\infty}-\mathbf{I}_{\mathbf{C}}\right)\right]$
Equation 8

Equation 9

where $a_{3}$ was the calibration parameter for DLC thickness measurement that was based on the intensity of the carbon signal only. This parameter was determined experimentally by constructing a working curve using known DLC thickness (measured by ESCA) and the intensity of the carbon signal measured by AES. IC $_{C}$ was the intensity of the carbon signal. $\mathbf{I}_{\mathbf{C}}{ }^{\infty}$ was the intensity of the carbon signal that had a DLC thickness greater than the critical thickness.

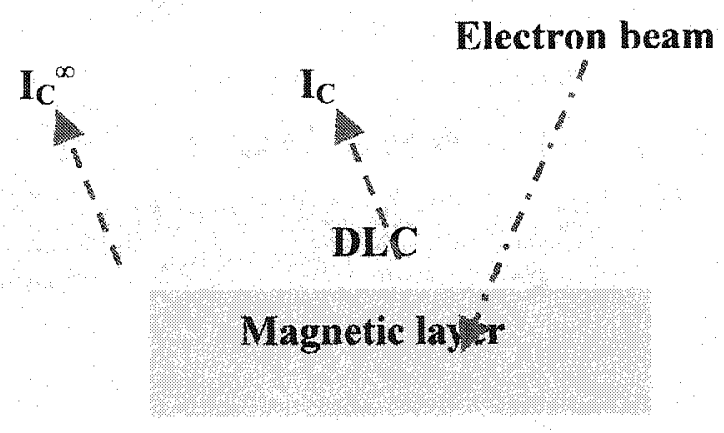

Figure 18. Schematic diagram of the carbon electrons emitted from thin DLC and infinite DLC 


\subsection{Verification and Statistical Analysis on the DLC Thickness Measured by AES}

\subsubsection{Verification of the DLC Thickness Measured by AES}

Four groups with expected DLC thickness $20 \AA, 30 \AA, 40 \AA$, and $50 \AA$ were used for verification. Each group had four disks. The DLC thicknesses of these samples were first measured by ESCA and then by AES.

\subsubsection{Statistical Analysis on the Difference in the DLC Thickness Measured by ESCA and AES}

The DLC thicknesses measured by ESCA could be expected to have a mean $\mu_{\mathrm{i}}$ and variance $\sigma_{\mathrm{i}}{ }^{2}$, while DLC thickness measured by AES would have a mean $\mu_{\mathrm{j}}$ and variance $\sigma_{j}^{2}$. The number of measurements by ESCA and AES were $n_{i}$ and $n_{j}$. A statistical procedure, the two-sample t-Test, was used to test statistically the differences of the means of the DLC thickness between what was measured by ESCA and AES.

The postulate was that the differences in means of DLC thicknesses measured by both methods were within a specified value $\mathrm{d}_{0}$. Therefore, the null hypothesis was:

$\mathrm{H}_{0}: \mu_{1}-\mu_{2} \leq \pm \mathrm{d}_{0}$

$\mathrm{H}_{1}: \mu_{1}-\mu_{2}> \pm \mathrm{d}_{0}$

where $\mu_{1}$ was the true mean of the DLC thickness determined by ESCA, $\mu_{2}$ was the true of the mean DLC thickness determined by AES, and $d_{0}$ was a controlled difference of those means. 
Assuming that the variances of the DLC thickness from both methods were the same, an appropriate test statistic to use for comparing the two true means was the $t$ statistic.

$t_{0}=\left(\overline{y_{1}}-\overline{y_{2}}\right)-\mathrm{d}_{0} / \mathrm{S}_{\mathrm{p}} \sqrt{1 / n_{1}+1 / n_{2}}$

Equation 10

where $\bar{y}_{1}$ and $\bar{y}_{2}$ were the sample means of the DLC thickness from ESCA and AES measurements, $n_{1}$ and $n_{2}$ were the numbers of the sample measurements from ESCA and $\mathrm{AES}$, and $\mathrm{S}_{\mathrm{p}}{ }^{2}$ was the pooled estimator of $\sigma^{2}$. Assuming that the variances of the DLC thickness from ESCA and AES were unknown but equal, $\sigma_{i}^{2}=\sigma_{j}^{2}=\sigma^{2}$, then $S_{p}{ }^{2}$ was specified by

$\mathrm{S}_{\mathrm{p}}^{2}=\left(\mathrm{n}_{1}-1\right) \mathrm{S}_{1}^{2}+\left(\mathrm{n}_{2}-1\right) \mathrm{S}_{2}^{2} /\left(\mathrm{n}_{1}+\mathrm{n}_{2}-2\right)$ Equation 11

where $\mathrm{S}_{1}^{2}$ and $\mathrm{S}_{2}^{2}$ were the sample variances from each method.

To determine whether to accept or reject the null hypotheses $H_{0}, \mu_{1}-\mu_{2} \leq \pm d_{0}$ was now straightforward; simply compare $t_{0}$ to the $t$ distribution with $n_{1}+n_{2}-2$ degrees of freedom. If $\left|t_{0}\right|>t_{\alpha / 2, n 1+n 2-2}$, the hypotheses $H_{0}$ would be rejected, and it would be concluded that the difference of the mean of the DLC thickness measured from both methods was larger than the specified value; otherwise, the difference of the mean of the DLC thickness was considered as being under the control value.

\subsubsection{Variability of the DLC Thickness between Disks}


Statistical analysis on the difference of the mean of the DLC thickness measured on different disks was also performed using the Two-sample $t$-Test, the same as the statistical analysis that was done on the differences in the means of the DLC thicknesses measured between ESCA and AES. The only difference was that the previous test was the test between two methods; the t-Test done here was the test on the means of the DLC thicknesses between the disks, measured with the same method, either ESCA or AES.

\subsection{Maximum Measurable DLC Thickness}

Measurement of the maximum measurable DLC thickness could be performed by calculation using the IMFP of cobalt or the intensity of the cobalt Auger signal.

The average depth, from which electrons escaped the near surface region without losing a significant portion of their energy, was often referred to as the escape depth [11]. When the escape depth was three times the IMFP, $95 \%$ of the Auger electrons were collected [12]. Therefore, the theoretical maximum measurable DLC thickness D could be estimated by

$\mathbf{D}=$ escape depth $=3$ IMFP $\quad$ Equation 12

In this case, IMFP was the inelastic mean free path of $C$ electrons at the energy of $750 \mathrm{eV}$ [4].

The maximum measurable DLC thickness could also be determined when the peaks of the cobalt signals in the AES spectra had disappeared. 


\section{CHAPTER FIVE}

\section{RESULTS AND DISCUSSIONS}

\subsection{Intensity of the Carbon Signal Measured by AES}

Carbon present in the DLC film but absent in the magnetic layer was excited by an electron beam, and the Auger electrons of carbon were emitted from the surface. Theoretically, if the DLC film was sufficiently thin, the intensity of carbon signal would increase with increased film thickness linearly. When the DLC thickness reached the critical thickness, there was no further increase in the carbon signal. However, the intensities of the carbon Auger signal were independent of the DLC thickness in the range of $18 \AA$ to $58 \AA$, as shown in Figure 19. As a result, the critical DLC thickness measured by AES was less than or equal to $18 \AA$.

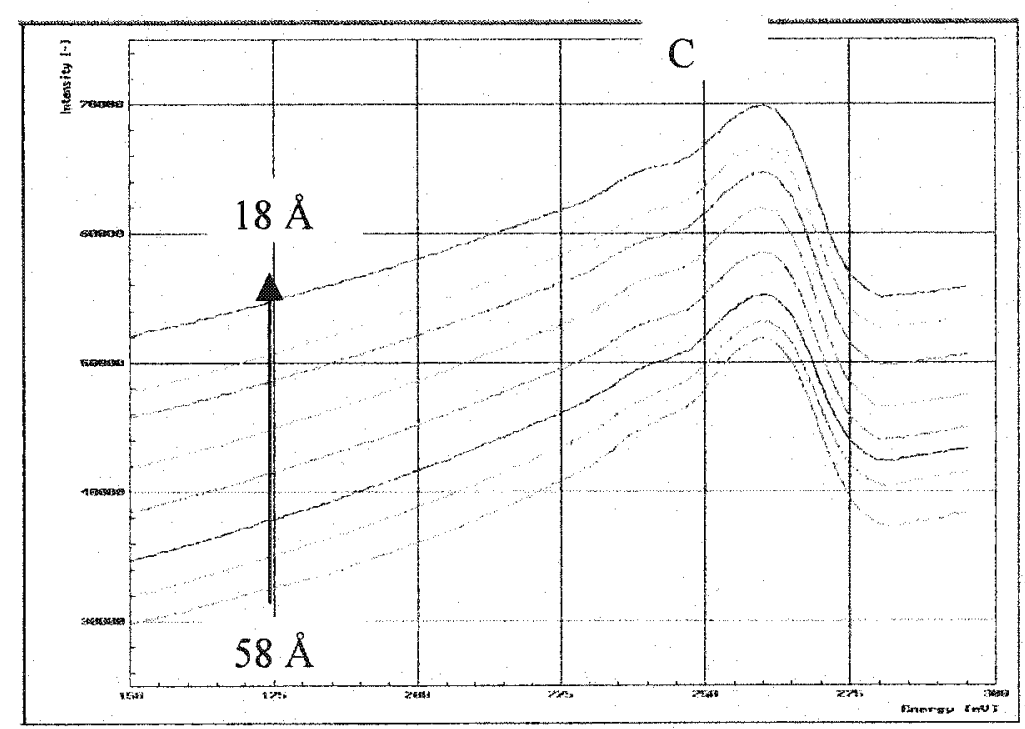

Figure 19. The intensities of carbon signal with different DLC thickness measured by AES 
The critical DLC thickness could be estimated by calculation and observation. Assuming the following to be true: (1) the intensity of carbon signal changed exponentially with the DLC thickness, and (2) there was no oxidation of cobalt occurring in the magnetic layer when the carbon thickness ranged from $13 \AA$ to $21 \AA$, in accordance with Beer's law, the critical carbon thickness could be calculated by [10]:

$\ln \left(1-\mathbf{I}_{\mathbf{d}} / \mathbf{I}_{\infty}\right)=-\mathbf{a}_{\mathbf{4}} \mathbf{d} \quad$ Equation 13

where $\mathbf{I}_{\mathbf{d}}$ and $\mathbf{I}_{\infty}$ were the intensities of the carbon signal with the DLC thickness less than, and more than, the critical carbon thickness, respectively. $\mathbf{d}$ was the DLC thickness. The parameter $a_{4}$ could be estimated from the ESCA DLC thicknesses that ranged from $13 \AA$ to $21 \AA$ and the intensities of the carbon signal measured by AES. When the ratio of $\mathbf{I}_{d} / \mathbf{I}_{\infty}$ was arbitrarily assigned a value of 0.99 , the critical DLC thickness was approximately $26 \AA$.

Figure 20 contains the intensities of the carbon signal as determined by AES, with the DLC thickness ranging from $13 \AA$ to $21 \AA$ in increments of $3 \AA$. It can be seen that the intensities of the carbon signal increased with increased DLC thickness, but ceased to vary very much when the DLC thickness was beyond $18 \AA$. This result indicates that the actual critical DLC thickness measured by AES was approximately $18 \AA$. 


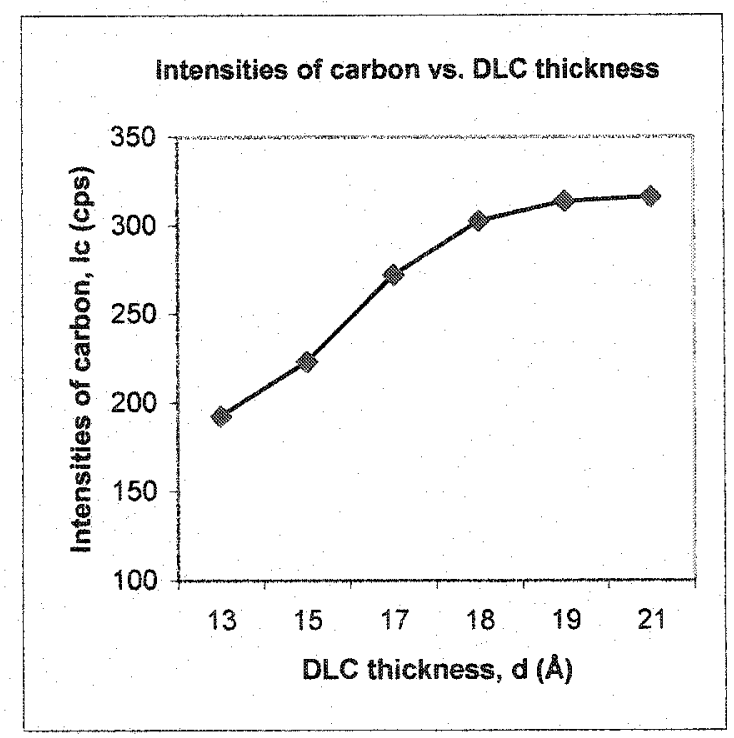

Figure 20. The intensities of carbon signal measured by AES with the DLC thickness ranging from $13 \AA$ to $21 \AA$

The critical DLC thickness determined by calculation and observation agreed within $30 \%$, and the difference presumably arose from the assumptions used to calculate the critical DLC thickness. Actually, when the DLC thickness was less than $18 \AA$, the intensity of the carbon signal had a nonlinear relationship with the DLC thickness, and Beer's law did not apply. Also, when the DLC thickness was less than $20 \AA$, the DLC coverage was apparently incomplete, allowing cobalt oxidation to occur in the magnetic layer [2].

Because the critical DLC thickness measured by AES was less than $18 \AA$, the DLC thickness measurement based on the intensity of the carbon signal in Case 1 (calculation of DLC thickness with the intensities of carbon and cobalt signals) and Case 
3 (calculation of DLC thickness with the intensities of carbon signal only) were invalid. Therefore, the DLC thickness measured by AES could only be performed with the intensity of cobalt signal from the magnetic layer, which was Case 2.

\subsection{The Change of the Intensity of Cobalt Signal with DLC Thickness Satisfies Beer-}

\section{Lambert Law}

Cobalt in the magnetic layer is excited by the electron beam and detected by AES, as shown in Figure 21. As expected, the intensities of the cobalt signal decreased as the DLC thicknesses increased, when the DLC thicknesses were in the range of $18 \AA$ to $58 \AA$.

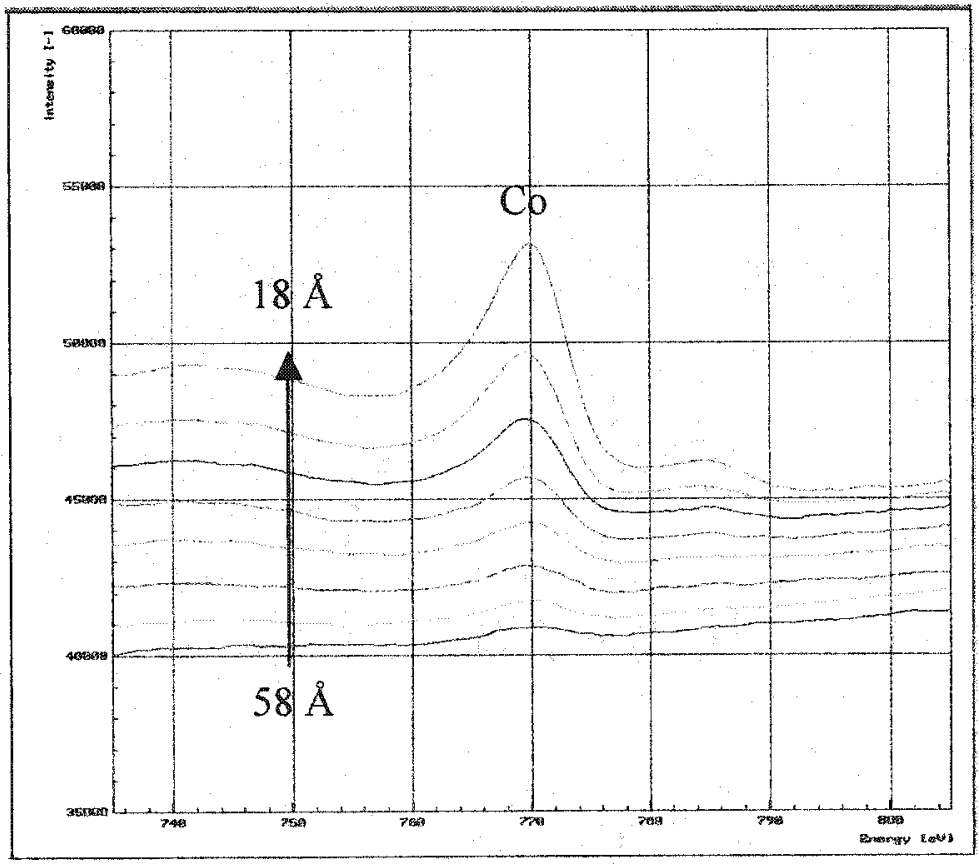

Figure 21. The intensities of the cobalt signal with different DLC thickness measured by AES 
Figure 22 contains the DLC thickness plotted as a function of the natural log of the ratio of the intensities of the cobalt signal measured with and without DLC. Both DLC thickness and intensities of the cobalt signal were from AES measurements for the DLC thickness ranging from $23 \AA$ to $50 \AA$. Data fitting indicates that the DLC thickness increased linearly with the natural $\log$ of the ratio of the intensities of the cobalt signals with and without DLC. According to the Beer-Lambert Law, when light of intensity $I_{i}$ passed through a slab of material of thickness $\mathbf{d}$ to obtain the intensity $\mathbf{I}_{\mathbf{f}}$, the $\log$ of the $\mathbf{I}_{\mathbf{f}}$ / $\mathrm{I}_{\mathrm{i}}$ versus $\mathrm{d}$ has a linear relationship. Therefore, the intensities of cobalt measured by AES obeyed Beer's law.

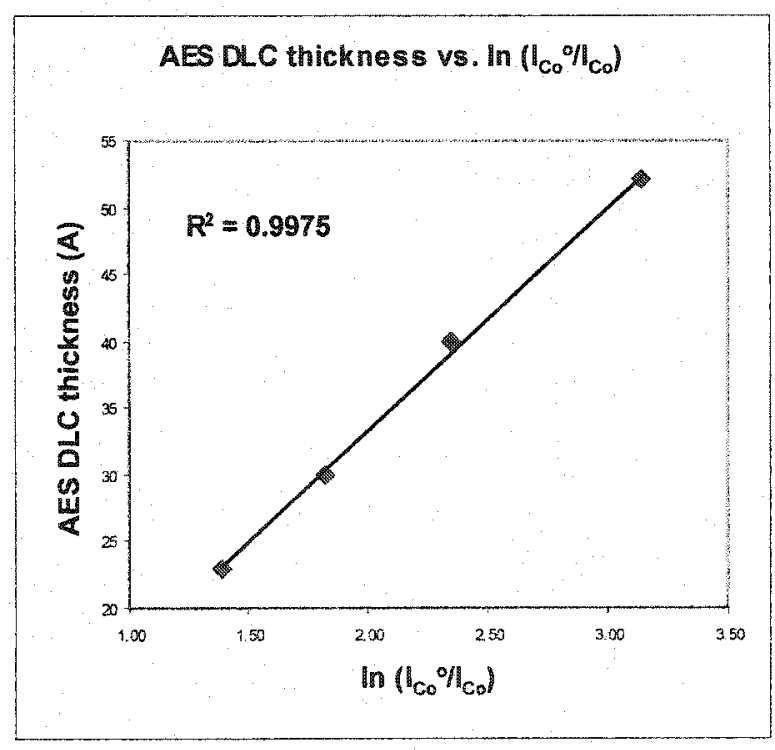

Figure 22. AES DLC thickness versus the natural log of the ratio of the intensities of cobalt without and with DLC 


\subsection{Calculation of Parameter " $a$ "}

As discussed previously, the parameter a was a calibration parameter that could be estimated by constructing a working curve using the DLC thickness measured by ESCA and the intensities of the cobalt signal from AES.

Figure 23 is a plot of the DLC thickness (measured by ESCA with the DLC thickness ranging from $18 \AA$ to $58 \AA$ ) versus the natural $\log$ of the ratio of the intensities of cobalt signal, with and without DLC, as measured by AES. Regression analysis of the data yielded a straight line, as represented by

$\mathrm{Y}=16.266 \mathrm{x}$ Equation 14

This result not only indicates that Beer's law can be applied to the intensities of the cobalt signal as it fell off with the DLC thickness, but also gave the slope of $\mathbf{1 6 . 2 6 6}$ for this linear relationship. By comparing Equation 14 with Equation 7, the parameter $\mathbf{a}_{2}$ was found to be equal to 16.266 .

While the value of the parameter " $\mathrm{a}$ " is generally dependent on the structure of the DLC and atomic concentration of Co in the magnetic layer, it is recommended that the calibration parameter " $a$ " be independently developed for each film-substrate system, using the method developed in this thesis. 


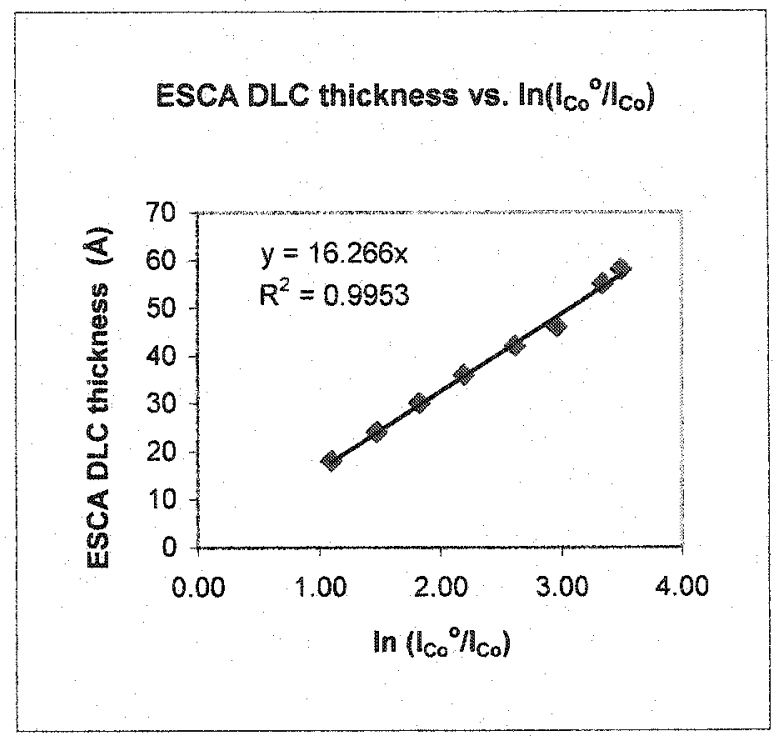

Figure 23. ESCA DLC thickness versus the natural log of the ratio of the intensities of cobalt signal without and with DLC

\subsection{DLC Thickness Calculation}

Bringing $\mathbf{a}_{2}=\mathbf{1 6 . 2 6 6}$ into Equation 7, the DLC thickness measured with AES could be calculated by

$$
\mathrm{d}=16.266 \ln \left(\mathrm{I}_{\mathrm{Co}^{\circ}} / \mathbb{I}_{\mathrm{Co}}\right)
$$

Equation 15

However, The DLC thickness that resulted from the intensities of the cobalt signal measured by AES had the following limitations: (1) The method was limited to carbon thickness ranging from $20 \AA$ to $58 \AA$. (2) The value of " $\mathrm{a}$ " in this equation was dependent on ESCA calibration. (3) The DLC thickness calculation was based on $60-70$ atom $\%$ of 
cobalt in the magnetic layer and 5 atom\% nitrogen in the DLC layer. (4) All measurements were performed on the disks without lubricant.

\subsection{Verification and Statistical Analysis}

\subsubsection{AES DLC Thickness Verification}

Four groups of disks, each group having four disks, were used for verification. The DLC thicknesses were first measured by ESCA with the resulting mean thickness of each group being $23 \AA, 30 \AA, 39 \AA$, and $49 \AA$. Later, these samples were measured by AES, and their DLC thicknesses were calculated with the Equation 15. Figure 24 contains the DLC thickness measured by ESCA and AES, and their linear correlation represented by $\mathrm{R}^{2}$. There was no significant difference in the means of the DLC thickness measured by ESCA and AES.

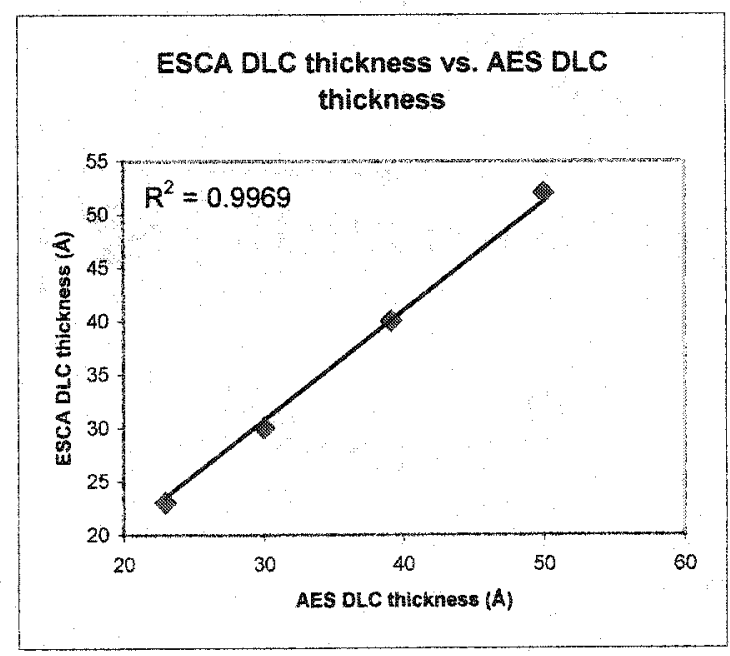

Figure 24. Comparison of the DLC thickness determined by ESCA and AES 


\subsubsection{Statistical Analysis on the Difference in the DLC Thickness Measured by}

\section{ESCA and AES}

A Two-sample t-Test was used to test the specified difference $\left(\mu_{\mathrm{i}}-\mu_{\mathrm{j}} \leq \pm \mathrm{d}_{0}\right)$ of the DLC thickness as measured by the two methods. This analysis was performed by assuming unknown but equal variances, $\sigma_{\mathrm{i}}^{2}=\sigma_{\mathrm{j}}^{2}$. The confidence level or $\alpha$-value was specified as $99 \%$ or 0.01 . Table III contains the results of the $t-T e s t$. Since $\left|t_{0}\right|<t_{0.005,50}$, the null hypothesis, $\mu_{1}-\mu_{2} \leq \pm d_{0}$, could not be rejected. That is, at a $99 \%$ confidence level, the mean differences of the DLC thickness measured with ESCA and AES were less than $1 \AA$ when the DLC thickness ranged from 23 to $39 \AA$. However, when the DLC thickness reached $50 \AA$, the difference increased to $2.6 \AA$.

Table III. Two-Sample T-Test Result for the DLC Thicknesses Measured with ESCA and

AES

\begin{tabular}{|c|c|c|c|c|c|c|c|c|}
\hline \multirow[b]{2}{*}{ Group } & \multicolumn{2}{|c|}{$\mathrm{ESCA}$} & \multicolumn{2}{|l|}{$\mathrm{AES}$} & \multicolumn{4}{|c|}{ T-Test } \\
\hline & $\begin{array}{l}\text { mean } \\
(\AA)\end{array}$ & StDev & $\begin{array}{l}\text { Mean } \\
(\AA)\end{array}$ & StDev & ||$t_{0} \mid$ & $t_{0,005,50}$ & $\mathrm{~d}_{0}(\AA)$ & Conclusion \\
\hline 1 & 23 & 0.5 & 23 & 0.3 & 0.26 & 2.69 & 0.7 & $\begin{array}{l}\left|t_{0}\right|<t_{0.005,50} \\
\text { AES mean }- \text { ESCA mean }=0.7 \AA \\
\text { with } 99 \% \text { confidence }\end{array}$ \\
\hline 2 & 30 & 0.7 & 30 & 0.4 & 0.31 & 2.69 & 0.3 & $\begin{array}{l}\left|t_{0}\right|<t_{0.005,50} \\
\text { AES mean - ESCA mean }=0.2 \AA \\
\text { with } 99 \% \text { confidence }\end{array}$ \\
\hline$\beta$ & 39 & 0.7 & 40 & 0.5 & 0.10 & 2.69 & 0.8 & $\begin{array}{l}\left|t_{0}\right|<t_{0,005,50} \\
\text { AES mean }- \text { ESCA mean }=0.9 \AA \\
\text { with } 99 \% \text { confidence }\end{array}$ \\
\hline 4 & 49 & 1.2 & 52 & 0.5 & 0.05 & 2.69 & 2.6 & $\begin{array}{l}\left|t_{0}\right|<t_{0.005,50} \\
\text { AES mean - ESCA mean }=2.6 \AA \\
\text { with } 99 \% \text { confidence }\end{array}$ \\
\hline
\end{tabular}


Figure 25 is a comparative box plot for the differences of the DLC thicknesses as measured by ESCA and AES. The comparative box plot indicates that the means of the DLC thickness measured by both methods practically coincided, although the group with DLC thickness $50 \AA$ had a slightly larger difference in the DLC thickness measured by ESCA and AES.

A comparitive boxplot for the carbon thickness measured by ESCA and AES

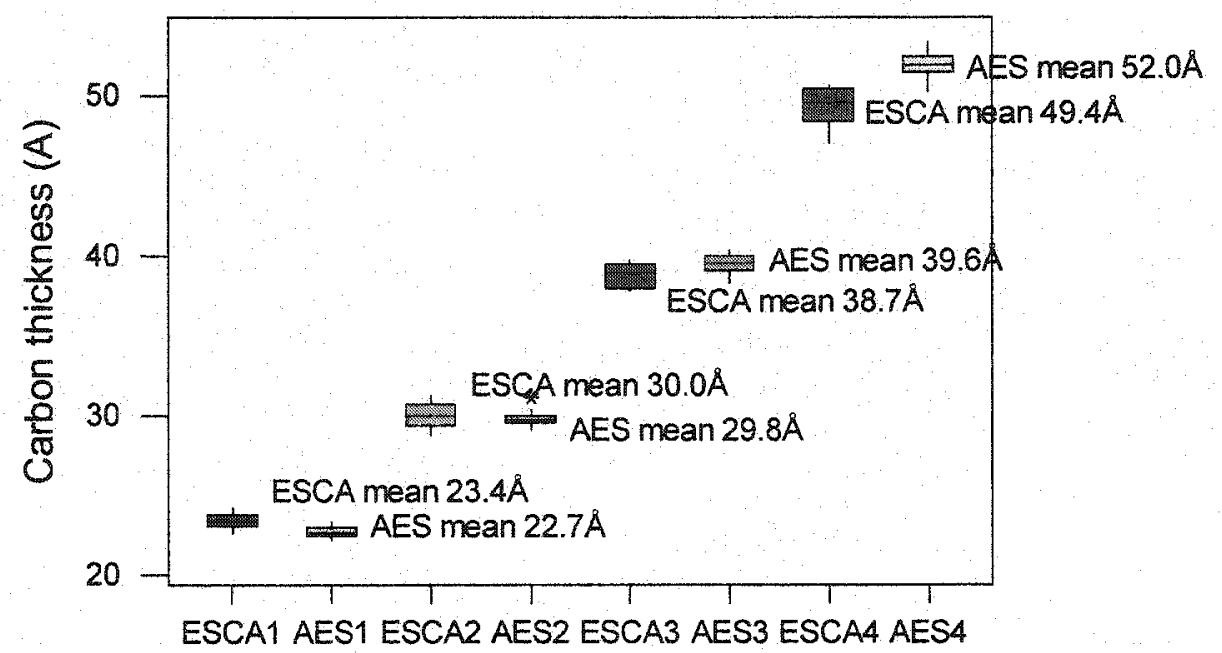

Figure 25. Comparative box plot for the DLC thickness measured by ESCA and AES

\subsubsection{Variability of the DLC Thickness between the Disks}

The variations of measurement represented by mean thickness between the disks were tested by using the Two-sample t-Test with a specified difference of the DLC 
thickness between two disks. The analysis was performed by assuming unknown but equal variance in the thickness of the disks. The confidence level or $\alpha$-value was specified as $99 \%$ or 0.01 . The data from six pairs of disks from the group with DLC thickness $39 \AA$ were analyzed statistically. Table IV includes the test results for ESCA, and Table V includes the test results for AES.

Table IV. Two-Sample T-Test Results for the DLC Thicknesses (39 $\AA$ ) Measured with ESCA between the Disks

\begin{tabular}{|c|c|c|c|}
\hline & \multicolumn{3}{|l|}{ T-Test } \\
\hline & $t_{0}$ & $t_{0.005,4}$ & Conclusion \\
\hline Disk1 / Disk2 & 0.007 & 4.604 & $\begin{array}{l}\text { When } d_{0}=1 \AA,\left|t_{0}\right|<t_{0.005,4} \text {, meaning that the DLC } \\
\text { thickness difference between two disks is within } 1 \AA \text { with } \\
99 \% \text { confidence }\end{array}$ \\
\hline Disk 1 / Disk3 & 0.012 & 4.604 & $\begin{array}{l}\text { When } d_{0}=1.2 \AA,\left|t_{0}\right|<t_{0.005,4} \text {, meaning that the } D L C \\
\text { thickness difference between two disks is within } 1.2 \AA \text { with } \\
99 \% \text { confidence }\end{array}$ \\
\hline Disk1 / Disk4 & -0.005 & 4.604 & $\begin{array}{l}\text { When } d_{0}=1 \AA,\left|t_{0}\right|<t_{0.005,4} \text {, meaning that the } D L C \\
\text { thickness difference between two disks is within } 1 \AA \text { with } \\
99 \% \text { confidence }\end{array}$ \\
\hline Disk2/ Disk3 & -0.001 & 4.604 & $\begin{array}{l}\text { When } d_{0}=0.2 \AA,\left|t_{0}\right|<t_{0.005,4} \text {, meaning that the } D L C \\
\text { thickness difference between two disks is within } 0.2 \AA \text { with } \\
99 \% \text { confidence }\end{array}$ \\
\hline Disk2 / Disk4 & -0.009 & 4.604 & $\begin{array}{l}\text { When } d_{0}=0 \AA,\left|t_{0}\right|<t_{0.005,4} \text {, meaning that the } D L C \\
\text { thickness difference between two disks is within } 0 \AA \text { with } \\
99 \% \text { confidence }\end{array}$ \\
\hline Disk3 / Disk4 & -0.011 & 4.604 & $\begin{array}{l}\text { When } d_{0}=0.2 \AA,\left|t_{0}\right|<t_{0} .005,4 \text {, meaning that the } D L C \\
\text { thickness difference between two disks is within } 0.2 \AA \text { with } \\
99 \% \text { confidence }\end{array}$ \\
\hline
\end{tabular}


Table V. Two-Sample T-Test Results for the DLC Thicknesses (39 $\AA$ ) Measured with

AES between the Disks

\begin{tabular}{|c|c|c|c|}
\hline & \multicolumn{3}{|c|}{ T-Test } \\
\hline & $t_{0}$ & $t_{0.005,18}$ & Conclusion \\
\hline Disk1 / Disk2 & 0.157 & 2.878 & $\begin{array}{l}\text { When do }=0.7 \AA, \mid \text { to } \mid<t_{0.005,}, 18 \text {, meaning that the DLC } \\
\text { thickness difference between two disks is within than } \\
0.7 \AA \text { with } 99 \% \text { confidence }\end{array}$ \\
\hline Disk1 / Disk3 & 0.060 & 2.878 & $\begin{array}{l}\text { When do }=0.4 \AA,|t o|<t_{0.005,18,} \text { meaning that the } D L C \\
\text { thickness difference between two disks is within } 0.4 \AA \text { with } \\
99 \% \text { confidence }\end{array}$ \\
\hline Disk1 / Disk4 & -0.212 & 2.878 & 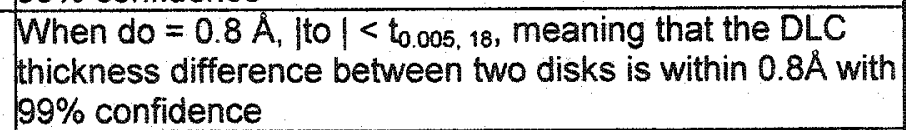 \\
\hline Disk2/ Disk3 & 0.222 & 2.878 & $\begin{array}{l}\text { When do }=0.2 \AA,|t o|<t_{0.005,18,} \text { meaning that the } D L C \\
\text { thickness difference between two disks is within } 0.2 \AA \text { with } \\
99 \% \text { confidence }\end{array}$ \\
\hline Disk2 / Disk4 & -0.058 & 2.878 & $\begin{array}{l}\text { When do }=0.1 \AA, \mid \text { to } \mid<t_{0.005,18} \text {, meaning that the } D L C \\
\text { thickness difference between two disks is within } 0.1 \AA \text { with } \\
99 \% \text { confidence }\end{array}$ \\
\hline Disk3 / Disk4 & 0.278 & 2.878 & $\begin{array}{l}\text { When do }=0.4 \AA \text {, |to } \mid<t_{0.005,18} \text {, meaning that the DLC } \\
\text { thickness difference between two disks is within } 0.4 \AA \text { with } \\
99 \% \text { confidence }\end{array}$ \\
\hline
\end{tabular}

The following conclusions can be drawn from the Two-sample t-Test of the differences of the means of the DLC thicknesses between disks measured by ESCA and AES:

- For the measurements from ESCA, the maximum difference of the mean was 1.2 $\AA$, which occured between Disk 1 and Disk 3. However, the differences of the DLC thicknesses were equal to, or less than, $0.2 \AA$ among Disks 2,3 , and 4.

- The measurements from AES were quite close. The differences of the means measured from different disks were within $1 \AA$. The maximum difference was 0.8 $\AA$, which occured between Disk 1 and Disk 4. 
- The measurements variation between disks, as measured by ESCA and AES, were acceptable in practice.

Figure 26 and Figure 27 contain the comparative box plots for the DLC thickness $(39 \AA)$ as measured by ESCA and AES. For ESCA, the measurements of all disks were almost equal except for that measured for Disk 1. The measurements by AES for all 4 disks were very close, with the differences being less than $1 \AA$.

Boxplot of the difference of ESCA DLC thickness $(39 \AA)$ between disks

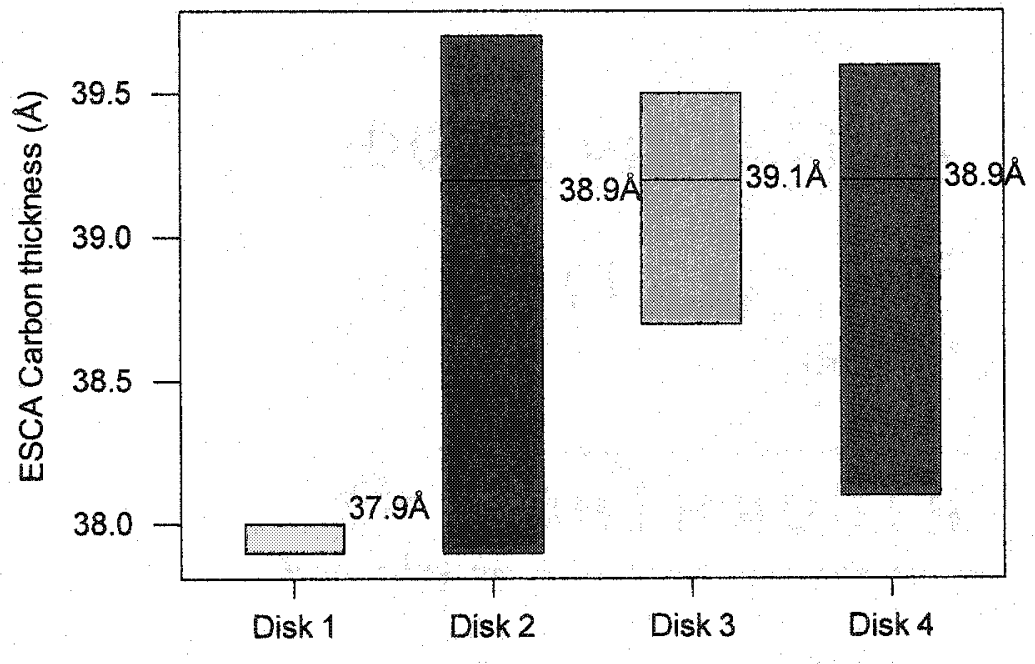

Figure 26. Comparative box plot of the DLC thickness ( $39 \AA$ ) measured by ESCA 


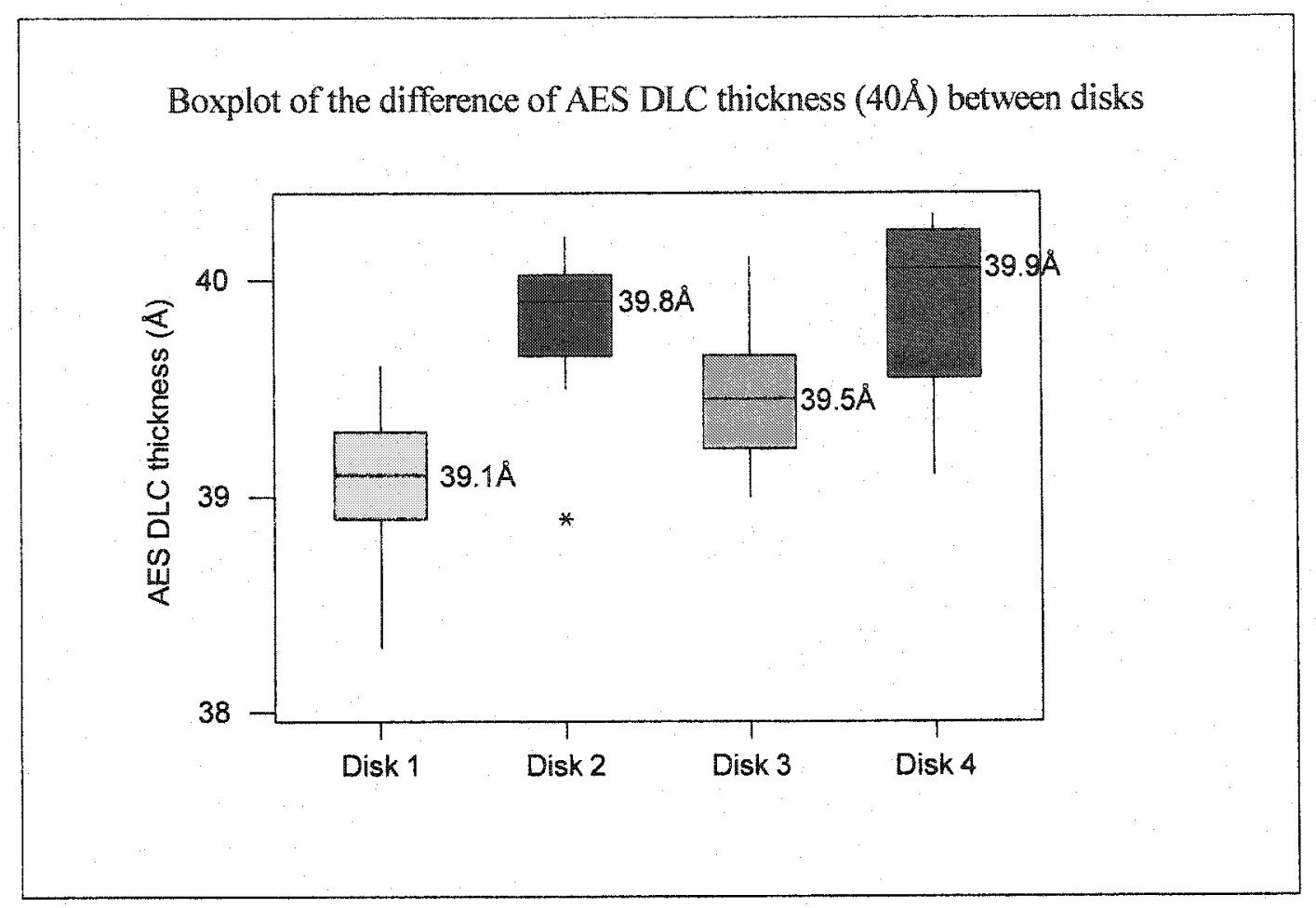

Figure 27. Comparative box plot of the DLC thickness ( $39 \AA)$ measured by AES

\subsection{Maximum Measurable DLC Thickness}

Figure 28 shows how the intensities of the cobalt signal changed with the DLC thicknesses measured by AES. When the DLC thickness reached $58 \AA$, the intensity of cobalt became undetectable. Therefore, the conclusion drawn was that the maximum measurable DLC thickness by AES was approximately $58 \AA$. 


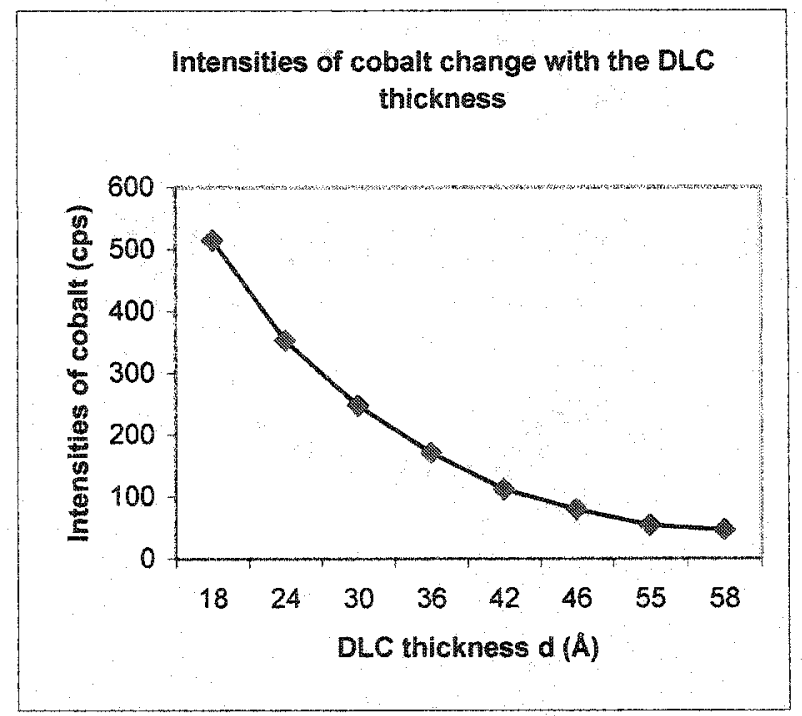

Figure 28. The intensities of cobalt change with the DLC thickness measured by AES

All measurements were performed at a sample tilt angle of $30^{\circ}$, which corresponded to an electron take-off angle, $\boldsymbol{\theta}$, of $65^{\circ}$. This difference in angle decreased the theoretical maximum measurable DLC thickness. With reference to Figure 29, it can be seen that the maximum measurable DLC thickness $\mathbf{D}$ - vertical depth - is given by

$$
\mathbf{D}=3 \text { IMFP } \sin \theta
$$

Equation 16

When the electron take-off angle $\theta$ was $65^{\circ}$ (sample tilt angle was $30^{\circ}$ ), probe energy $10 \mathrm{keV}$, and IMFP of $\mathrm{C}$ at $750 \mathrm{eV}$ was $23 \AA$ [4], the theoretical maximum measurable carbon thickness was $\mathbf{5 5} \AA$. 


\section{Electron beam}

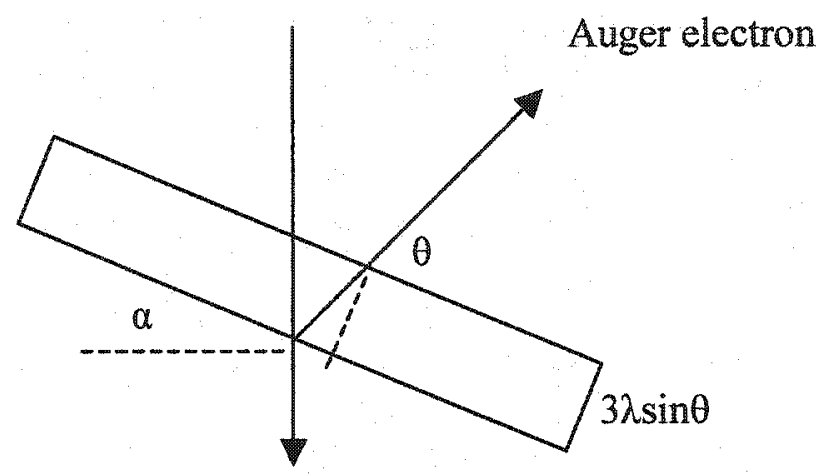

Figure 29. The escape depth variation with the electron take-off angle

The maximum measurable carbon thicknesses determined by calculation and observation agreed within $5 \%$. The difference was primarily due to the variation between the theoretical and real IMFP. 


\section{CHAPTER SIX}

\section{CONCLUSION}

DLC thicknesses can be measured with AES by using the intensities of cobalt signal. When an electron beam is allowed to irradiate the surface of a magnetic disk, carbon and cobalt electrons are emitted from the DLC and magnetic layer. The intensities of the carbon signal remained constant for the DLC thicknesses ranging from $18 \AA$ to 58 $\AA$. The critical carbon thickness was approximately $18 \AA$. However, the intensities of the cobalt signal decreased as the DLC thickness increased, for DLC thicknesses ranging from $18 \AA$ to $58 \AA$. The DLC thickness changed with the natural log of the ratio of the intensities of the cobalt signal, with and without changes in DLC thickness, had a linear relationship and obeyed Beer's law. The parameter "a" calculated by constructing a working curve, based on ESCA DLC thickness and the intensities of the cobalt signal measured by AES, was $16.266 \AA$. The DLC thickness measured by AES can be calculated by Equation 15,

$d=16.266 \ln \left(I_{\mathrm{Co}^{\circ}} / I_{\mathrm{Co}}\right)$

where $\mathbf{I}_{\mathbf{C}_{0}}{ }^{\circ}$ and $\mathbf{I}_{\mathbf{C o}}$ are the intensities of cobalt signal without and with DLC. The maximum measurable DLC thickness with an electron take-off angle of $65^{\circ}$ at the probe energy $10 \mathrm{keV}$ was approximately $\mathbf{5 8 \AA}$. 
At a $99 \%$ confidence level, the mean differences in the DLC thickness measured by AES and ESCA were less than $1 \AA$ when the DLC thickness ranged from 23 to $39 \AA$. The difference increased to $2.6 \AA$ when the DLC thickness reached $50 \AA$. The mean differences measured by either ESCA or AES between disks were less than $1.2 \AA$ when the DLC thickness was $39 \AA$.

While the value of the parameter " $a$ " is generally dependent on the structure of the DLC and atomic concentration of $\mathrm{Co}$ in the magnetic layer, it is recommended to generate a different calibration parameter " $a$ " for different film-substrate combination, using the method developed in this investigation. 


\section{CHAPTER SEVEN \\ RECOMMENDATIONS}

It was possible to accurately measure DLC thickness with AES. However, potential errors might occur in the measurements due to a variety of factors such as changes in the density of DLC, non-negligible surface roughness, and non-exponential attenuation of the signal electrons caused by the effects of elastic scattering of the signal [15]. Therefore, further studies associated with the DLC thickness measured by AES should include:

- The extent of the effects caused by different DLC structures and changes in density on IMFP

- Effect of different surface roughness on the DLC thickness measurements

- Effect of current intensity of the electron gun on the DLC thickness measurements

- Effect of Electron take off angle on the measurements

- Effect of lubricant on the surface of a disk on the DLC thickness measurements 


\section{REFERENCES}

1. W. Xu, L.J. Huang, Y.Z. shih, T. Kim, Y. Hung and G. Li, "Substrate Induced DLC Film Thickness Variations," Thin Solid films, 355-356 (1999).

2. C.M. Mate, B.K. Yen, D.C. Miller, M.F. Toney, M. Scarpulla and J.E. Frommer, "New Methodologies for Measuring Film Thickness, Coverage, and Topography," IEEE Transactions On Magnetics, Vol. 36, No 1 (January 2000).

3. G. Barth and L.J. Huang, "Carbon Film Thickness Measurement on Disk Media Using ESCA," unpublished results (1999).

4. S. Tanuma, C.J. Powell and D.R. Penn, "Calculations of Electron Inelastic Mean Free Paths," Surface And Interface Analysis, Vol. 17, 911-926 (1991).

5. B. Ziaja, D.V.D. Spoel, A. Szoke and J. Hajdu, "Auger-electron cascades in diamond and amorphous carbon," Physical Review B, Vol. 64, 214104 (2001).

6. ASM Handbook, Materials Characterization, $9^{\text {th }}$.ed. Vol.10, pp. 550-567 (1998).

7. G.C. Smith, "Surface Analysis by Electron Spectroscopy," (Plenum Press. New York and London), pp. 6-14 (date?).

8. P.W. Atkins, Physical Chemistry, $2^{\text {nd }}$ ed. Oxford Univ. Press. Great Britain, pp. 604605 (1982).

9. “Media Manufacturing Basics," knowledgeTek, pp.1-85 (1998).

10. E.F. Kaelble, Handbook of X-Ray, McGraw-Hill, New York, pp. $441-4411$ (1967).

11. D. Briggs and M.P. Seah, "Practical Surface Analysis," John Wiley \& Sons Ltd., pp.133 (1984).

12. I.F. Ferguson, “Auger Microprobe Analysis," IOP Publishing Ltd, pp.1-16 (1989). 
13. Y. Zheng, Seagate, unpublished data (July 2003).

14. S. Baumann, "Outsourcing of Analysis: Choosing the Right Technique," Microelectronic Failure Analysis Desk Reference 2002 Supplement.

15. K. Nishimori, K. Tanaka and K. Sato, "Evaluation of the electron attenuation length for the determination of the lubricant overlayer thickness on magnetic disks with $x$ ray photoelectron spectroscopy," Journal of Vacuum Science \& Technology, Vol. 8, pp.3653-3892 (1990).

16. H. Tsai and D.B. Bogy, "Characterization Of Diamond-Like Carbon Films And Their Application As Overcoats On Thin-Film Media For Magnetic Recording," Journal of Vacuum Science \& Technology, A5(6) (1987).

17. A. Jablonski, C.J. Powell, "The electron attenuation length revised," Surface Science Reports, 47, pp.33-91 (2002). 


\section{APPENDIX A}

\section{Raw Data and Calculation for Establishing an Equation}

\section{to Measure the DLC Thickness by AES}

The method to measure the DLC thickness by AES was established based on the disks with the DLC thickness $18 \AA, 24 \AA, 30 \AA, 36 \AA, 42 \AA, 46 \AA, 55 \AA$ and $58 \AA$.

Table VI. ESCA DLC Thickness and Intensities of Carbon and Cobalt Signals Measured by AES

\begin{tabular}{|c|c|c|c|c|c|c|c|c|c|c|c|c|}
\hline \multirow{2}{*}{ ESCA-d $(\AA)$} & \multirow{2}{*}{ AES } & \multicolumn{10}{|c|}{ Scan (cps) } & \multirow[t]{2}{*}{ Average } \\
\hline & & 1 & 2 & 3 & 4 & 5 & 6 & 7 & 8 & 9 & 10 & \\
\hline \multirow{2}{*}{18} & $I_{C}$ & 558 & 582 & 510 & 512 & 500 & 520 & 511 & 500 & 499 & 506 & 520 \\
\hline & $I_{c o}$ & 579 & 568 & 507 & 486 & 489 & 497 & 517 & 502 & 509 & 490 & 514 \\
\hline \multirow{2}{*}{24} & $I_{C}$ & 526 & 532 & 541 & 530 & 518 & 515 & 521 & 526 & 512 & 532 & 525 \\
\hline & $l_{c o}$ & 369 & 338 & 337 & 351 & 364 & 337 & 359 & 363 & 351 & 357 & 353 \\
\hline \multirow{2}{*}{30} & Ic & 580 & 555 & 548 & 539 & 544 & 551 & 544 & 576 & 537 & 557 & 553 \\
\hline & lco & 239 & 251 & 253 & 252 & 255 & 242 & 248 & 256 & 245 & 234 & 248 \\
\hline \multirow{2}{*}{36} & $l_{c}$ & 539 & 554 & 571 & 557 & 566 & 559 & 566 & 567 & 551 & 563 & 559 \\
\hline & $I_{C o}$ & 166 & 170 & 173 & 177 & 175 & 166 & 162 & 168 & 176 & 181 & 171 \\
\hline \multirow{2}{*}{42} & ic & 555 & 544 & 544 & 555 & 559 & 565 & 550 & 570 & 544 & 545 & 553 \\
\hline & Ico & 115 & 117 & 103 & 113 & 98 & 129 & 103 & 115 & 112 & 119 & 112 \\
\hline \multirow{2}{*}{46} & $I_{c}$ & 563 & 574 & 585 & 579 & 553 & 565 & 568 & 554 & 576 & 579 & 570 \\
\hline & Ico & 93 & 89 & 84 & 94 & 83 & 98 & 92 & 87 & 89 & 86 & 90 \\
\hline \multirow{2}{*}{55} & $I_{C}$ & 520 & 520 & 509 & 512 & 532 & 528 & 527 & 540 & 538 & 529 & 526 \\
\hline & I co & 55 & 58 & 53 & 41 & 56 & 55 & 65 & 52 & 56 & 51 & 54 \\
\hline \multirow{2}{*}{58} & $I_{c}$ & 578 & 576 & 572 & 578 & 569 & 561 & 581 & 578 & 567 & 587 & 575 \\
\hline & $I_{C o}$ & 47 & 46 & 69 & 38 & 52 & 40 & 57 & 36 & 41 & 38 & 46 \\
\hline
\end{tabular}


Table VII Summary of the AES Results

\begin{tabular}{|l|l|l|l|l|l|l|l|l|}
\hline ESCA-d $(\AA)$ & 18 & 24 & 30 & 36 & 42 & 46 & 55 & 58 \\
\hline$I_{\text {C }}$ (cps) & 520 & 525 & 553 & 559 & 553 & 570 & 526 & 575 \\
\hline Ico $_{\text {c }}$ cps $)$ & 514 & 353 & 248 & 171 & 112 & 90 & 54 & 46 \\
\hline
\end{tabular}

Table VIII. Intensities of Cobalt Signal without DLC Thickness as Measured by AES

\begin{tabular}{|l|l|l|l|l|l|l|l|l|l|l|l|}
\hline Scan & 1 & 2 & 3 & 4 & 5 & 6 & 7 & 8 & 9 & 10 & Average \\
\hline$l_{\mathrm{Co}}^{\circ}(\mathrm{cps})$ & 1514 & 1510 & 1534 & 1535 & 1532 & 1545 & 1541 & 1537 & 1545 & 1549 & 1534 \\
\hline
\end{tabular}

Table IX. Calculation of Parameter " $a$ " with the Equation: $d=a_{2} \ln \left(I_{C o}{ }^{\circ} / I_{C o}\right)$

\begin{tabular}{|l|l|l|l|l|l|l|l|l|}
\hline ESCA-d $(\AA)$ & 18 & 24 & 30 & 36 & 42 & 46 & 55 & 58 \\
\hline$\left.I_{\mathrm{Co}^{\circ}}{ }^{\circ} \mathrm{cps}\right)$ & 1534 & 1534 & 1534 & 1534 & 1534 & 1534 & 1534 & 1534 \\
\hline $\mathrm{I}_{\mathrm{Co}}(\mathrm{cps})$ & 514 & 353 & 248 & 171 & 112 & 90 & 54 & 46 \\
\hline $\ln \left(\mathrm{I}_{\mathrm{Co}}{ }^{\circ} / \mathrm{lco}\right)$ & 1.09 & 1.47 & 1.82 & 2.19 & 2.61 & 2.84 & 3.34 & 3.50 \\
\hline $\mathrm{a}$ & 16.47 & 16.32 & 16.44 & 16.43 & 16.07 & 16.22 & 16.45 & 16.58 \\
\hline
\end{tabular}




\section{APPENDIX B}

\section{Raw Data and Calculation of Verification and Statistical Analysis}

\section{of the DLC Thickness Measured by AES}

Verification and statistic analysis were performed on 4 disks and 4 groups of disks with the DLC thickness $23 \AA, 30 \AA, 39 \AA$, and $49 \AA$.

Table X. ESCA DLC Thickness Measurements

\begin{tabular}{|c|c|c|c|c|c|}
\hline \multirow{2}{*}{ Group } & \multirow{2}{*}{\begin{tabular}{|l|} 
Disk \\
Disk 1
\end{tabular}} & \multicolumn{3}{|c|}{$\operatorname{ESCA}(\AA)$} & \multirow{2}{*}{$\begin{array}{l}\text { Average } \\
23\end{array}$} \\
\hline & & 23 & 23 & 23 & \\
\hline & Disk 2 & 23 & 24 & 23 & 23 \\
\hline & Disk 3 & 24 & 24 & 23 & 23 \\
\hline & Disk 4 & 24 & 24 & 23 & 24 \\
\hline \multirow[t]{4}{*}{2} & Disk 1 & 30 & 29 & 29 & 29 \\
\hline & Disk 2 & 30 & 30 & 30 & 30 \\
\hline & Disk 3 & 31 & 31 & 30 & 30 \\
\hline & Disk 4 & 31 & 31 & 29 & 30 \\
\hline \multirow[t]{4}{*}{3} & Disk 1 & 38 & 38 & 38 & 38 \\
\hline & Disk 2 & 40 & 39 & 38 & 39 \\
\hline & Disk 3 & 39 & 40 & 39 & 39 \\
\hline & Disk 4 & 40 & 39 & 38 & 39 \\
\hline \multirow[t]{4}{*}{4} & Disk 1 & 49 & 48 & 47 & 48 \\
\hline & Disk 2 & 50 & 50 & 49 & 49 \\
\hline & Disk 3 & 51 & 50 & 48 & 50 \\
\hline & Disk 4 & 51 & 51 & 49 & 50 \\
\hline
\end{tabular}


Table XI. AES based DLC Thickness Measurements

\begin{tabular}{|c|c|c|c|c|c|c|c|c|c|c|c|}
\hline Group & \multicolumn{10}{|c|}{ AES $(\AA)$} & Average \\
\hline 1 & 23 & 23 & 23 & 23 & 23 & 23 & 23 & 23 & 23 & 23 & 23 \\
\hline & 23 & 23 & 23 & 23 & 23 & 23 & 23 & 22 & 22 & 22 & 23 \\
\hline & 23 & 23 & 23 & 23 & 23 & 23 & 23 & 23 & 23 & 22 & 23 \\
\hline & 23 & 23 & 22 & 22 & 22 & 22 & 23 & 22 & 22 & 22 & 22 \\
\hline 2 & 30 & 30 & 30 & 30 & 30 & 29 & 30 & 30 & 30 & 29 & 30 \\
\hline & 30 & 30 & 30 & 29 & 29 & 30 & 29 & 30 & 30 & 30 & 30 \\
\hline & 31 & 30 & 30 & 30 & 30 & 30 & 30 & 30 & 30 & 30 & 30 \\
\hline & 30 & 30 & 29 & 30 & 30 & 30 & 30 & 29 & 30 & 29 & 30 \\
\hline 3 & 39 & 39 & 39 & 39 & 39 & 39 & 38 & 40 & 39 & 39 & 39 \\
\hline & 39 & 40 & 39 & 40 & 40 & 40 & 40 & 40 & 40 & 40 & 40 \\
\hline & 39 & 39 & 39 & 40 & 39 & 39 & 40 & 39 & 40 & 39 & 39 \\
\hline & 40 & 40 & 39 & 40 & 39 & 40 & 40 & 40 & 40 & 40 & 40 \\
\hline 4 & 52 & 52 & 51 & 52 & 51 & 50 & 51 & 51 & 52 & 51 & 51 \\
\hline & 53 & 53 & 51 & 52 & 53 & 53 & 52 & 53 & 52 & 52 & 52 \\
\hline & 53 & 52 & 52 & 52 & 52 & 52 & 53 & 53 & 52 & 53 & 52 \\
\hline & 52 & 52 & 51 & 52 & 52 & 52 & 52 & 51 & 52 & 52 & 52 \\
\hline
\end{tabular}

Table XII. Differences of the DLC Thicknesses Measured by ESCA and AES

\begin{tabular}{|c|c|c|c|c|c|c|c|c|c|c|c|c|c|}
\hline Group 1 & & & & & & & & & & & & & \\
\hline $\mathrm{ECSA}$ & & & & AES & & & & & & & & & \\
\hline \multirow[t]{6}{*}{ Mean } & 23.37 & & & Mean & 22.70 & & & & & & & & \\
\hline & $\left(y_{i j}-y_{i}\right)^{2}$ & & & $\left(y_{i j}-y_{i}\right)^{2}$ & & & & & & & & & \\
\hline & 0.05 & 0.05 & 0.05 & 0.34 & 0.14 & 0.23 & 0.02 & 0.07 & 0.16 & 0.23 & 0.32 & 0.02 & .148 \\
\hline & 0.00 & 0.03 & 0.01 & 0.11 & 0.00 & 0.01 & 0.00 & 0.00 & 0.07 & 0.04 & 0.14 & 0.11 & .054 \\
\hline & 0.24 & 0.02 & 0.43 & 0.03 & 0.05 & 0.00 & 0.01 & 0.01 & 0.00 & 0.00 & 0.00 & 0.02 & .104 \\
\hline & 0.70 & 0.34 & 0.66 & 0.00 & 0.03 & 0.11 & 0.07 & 0.12 & 0.23 & 0.02 & 0.14 & 0.06 & .156 \\
\hline$\sum_{\left(y_{i j}-y_{i e}\right)^{2}}$ & 2.57 & & & $\sum_{\left(y_{i i}-y_{i i}\right)^{2}}$ & 3.40 & & & & & & & & \\
\hline \multirow[t]{2}{*}{$\mathrm{S}_{\mathrm{ESCA}}^{2}$} & 0.23 & & . & $\mathrm{S}_{\mathrm{AES}}$ & 0.09 & & & & & & & & \\
\hline & & & & Conclusion: & & & & & & & & & \\
\hline$\frac{S_{p}^{2}}{0.12}$ & \begin{tabular}{|l}
$S_{p}$ \\
0.35 \\
\end{tabular} & $\frac{t_{0}}{-0.26}$ & $\frac{t 0.005,50}{2.69}$ & $\begin{array}{l}\text { When } d_{o}=0.7 \\
\text { measured by t }\end{array}$ & $\begin{array}{l}A,\left|t_{0}\right| \\
\text { wo metl }\end{array}$ & $\begin{array}{l}<\mathrm{t}_{0.005} \\
\text { hods is }\end{array}$ & $\begin{array}{l}\text { so. me } \\
\text { withir }\end{array}$ & $\begin{array}{l}\text { aning tl } \\
\text { n } 0.7 \AA\end{array}$ & $\begin{array}{l}\text { hat the } 1 \\
\text { with } 99 \\
\end{array}$ & $\begin{array}{l}\mathrm{DLC} \text { th } \\
\% \text { conf }\end{array}$ & $\begin{array}{l}\text { hicknes } \\
\text { fidence }\end{array}$ & s diff & \\
\hline
\end{tabular}




\begin{tabular}{|c|c|c|c|c|c|c|c|c|c|c|c|c|c|}
\hline Group 2 & & & & & & & & & & & & & \\
\hline $\mathrm{ESCA}$ & & & & AES & & & & & & & & & \\
\hline \multirow[t]{7}{*}{ Mean } & 30.03 & & & Mean & 29.78 & & & & & & & & \\
\hline & $\left(y_{i j}-y_{i}\right)^{2}$ & & & $\left(y_{i j}-y_{i}\right)^{2}$ & & & & & & & & & \\
\hline & 0.26 & 0.53 & 0.57 & 0.01 & 0.01 & 0.00 & 0.14 & 0.00 & 0.14 & 0.03 & 0.03 & 0.22 & 0.44 \\
\hline & 0.15 & 0.05 & 0.11 & 0.01 & 0.04 & 0.00 & 0.11 & 0.37 & 0.04 & 0.22 & 0.05 & 0.03 & 0.02 \\
\hline & 0.43 & 0.57 & 0.13 & 1.87 & 0.19 & 0.01 & 0.00 & 0.16 & 0.00 & 0.06 & 0.02 & 0.31 & 0.15 \\
\hline & 1.38 & 0.45 & 1.41 & 0.00 & 0.01 & 0.14 & 0.04 & 0.05 & 0.02 & 0.25 & 0.09 & 0.06 & 0.10 \\
\hline & $\sum_{\left(y_{i j}-y_{i}\right)^{2}}$ & 6.04 & & $\sum_{\left.y_{i j}-y_{i}\right)^{2}}$ & 5.42 & & & & & & & & \\
\hline \multirow[t]{2}{*}{$\mathrm{S}^{2} \mathrm{ESCA}$} & 0.55 & & & $\mathrm{~S}_{\mathrm{AES}}^{2}$ & 0.14 & & & & & & & & \\
\hline & & & & Conclusion & & & & & & & & & \\
\hline $\mathrm{S}_{\mathrm{p}}^{2}$ & $s_{p}$ & $t_{0}$ & $t_{0.005,50}$ & \multirow{2}{*}{\multicolumn{10}{|c|}{$\begin{array}{l}\text { When } d_{o}=0.2 \AA,\left|t_{0}\right|<t_{0.005}, 50 \text {, meaning that the DLC thickness difference } \\
\text { measured by two methods is within } 0.3 \AA \text { with } 99 \% \text { confidence }\end{array}$}} \\
\hline 0.23 & 0.48 & -0.31 & 2.69 & & & & & & & & & & \\
\hline
\end{tabular}

\begin{tabular}{|c|c|c|c|c|c|c|c|c|c|c|c|c|c|}
\hline Group 3 & & & & & & & & & & & & & \\
\hline $\mathrm{ESCA}$ & & & & $\mathrm{AES}$ & & & & & & & & & \\
\hline \multirow[t]{7}{*}{ Mean } & 38.75 & & & Mean & 39.56 & & & & & & & & \\
\hline & $\left(y_{i j}-y_{i}\right)^{2}$ & & & $\left(y_{i j}-y_{i o}\right)^{2}$ & & & & & & & & & \\
\hline & 0.53 & 0.71 & 0.69 & 0.12 & 0.30 & 0.06 & 0.19 & 0.25 & 0.05 & 1.59 & 0.00 & 0.18 & 0.85 \\
\hline & 0.99 & 0.17 & 0.66 & 0.01 & 0.08 & 0.42 & 0.17 & 0.03 & 0.24 & 0.47 & 0.15 & 0.32 & 0.02 \\
\hline & 0.23 & 0.60 & 0.00 & 0.01 & 0.01 & 0.07 & 0.04 & 0.28 & 0.02 & 0.34 & 0.03 & 0.01 & 0.26 \\
\hline & 0.72 & 0.17 & 0.41 & 0.28 & 0.44 & 0.02 & 0.00 & 0.18 & 0.17 & 0.37 & 0.53 & 0.53 & 0.17 \\
\hline & $\sum_{\left(y_{i j}-y_{i i}\right)^{2}}$ & 5.86 & & $\sum_{\left(y_{i j}-y_{i .}\right)^{2}}$ & 7.94 & & & & & & & & \\
\hline \multirow[t]{2}{*}{$\mathrm{S}_{\mathrm{ESCA}}^{2}$} & 0.53 & & & $\mathrm{~S}_{\text {AES }}^{2}$ & 0.20 & & & & & & & & \\
\hline & & & & Conclusion & & & & & & & & & \\
\hline$S_{p}^{2}$ & $S_{p}$ & $t_{0}$ & $t_{0.005,50}$ & \multirow{2}{*}{\multicolumn{10}{|c|}{$\begin{array}{l}\text { When } d_{o}=0.9 \AA,\left|t_{0}\right|<t_{0.005}, 5_{0} \text { meaning that the DLC thickness difference } \\
\text { measured by two methods is within } 0.8 \AA \text { with } 99 \% \text { confidence }\end{array}$}} \\
\hline 0.28 & 0.53 & 0.10 & 2.69 & & & & & & & & & & \\
\hline
\end{tabular}




\begin{tabular}{|c|c|c|c|c|c|c|c|c|c|c|c|c|c|}
\hline Group & & & & & & & & & & & & & \\
\hline ESCA & & & & AES & & & & & & & & & \\
\hline Mean & 49.37 & & & Mean & 51.98 & & & & & & & & \\
\hline & $\left(y_{i j}-y_{i} \cdot\right)^{2}$ & & & $\left(y_{i j}-y_{i}\right)^{2}$ & & & & & & & & & \\
\hline & 0.08 & 2.19 & 5.31 & 0.14 & 0.02 & 0.33 & 0.14 & 1.53 & 2.96 & 0.55 & 0.71 & 0.22 & 1.96 \\
\hline & 0.18 & 0.24 & 0.29 & 0.59 & 0.48 & 0.29 & 0.01 & 0.91 & 0.54 & 0.05 & 2.09 & 0.01 & 0.16 \\
\hline & 1.47 & 0.84 & 0.99 & 0.39 & 0.19 & 0.16 & 0.04 & 0.03 & 0.26 & 0.54 & 1.39 & 0.02 & 0.44 \\
\hline & 1.65 & 1.47 & 0.01 & 0.01 & 0.22 & 0.40 & 0.00 & 0.26 & 0.00 & 0.06 & 0.28 & 0.07 & 0.04 \\
\hline & $\sum_{\left(y_{i i}-y_{i}\right)^{2}}$ & 14.73 & & $\sum_{\left(y_{i i}-y_{i}\right)^{2}}$ & 15.91 & & & & & & & & \\
\hline$S^{2}$ ESCA & 1.34 & & & $S^{2}{ }_{\text {AES }}$ & 0.41 & & & & & & & & \\
\hline & & & & Conclusion & & & & & & & & & \\
\hline $\mathrm{S}_{\mathrm{p}}^{2}$ & $S_{p}$ & $t_{0}$ & $t_{0.005,50}$ & $\begin{array}{l}\text { ien } d_{o}=2 \\
\text { asured by }\end{array}$ & $\begin{array}{l}6 \AA,\left|t_{0}\right| \\
\text { two me }\end{array}$ & $t_{0.0}$ & $\begin{array}{l}\text { me } \\
\text { thi }\end{array}$ & ning th & $\begin{array}{l}\text { at the D } \\
\text { vith } 999^{\circ}\end{array}$ & $\begin{array}{l}\text { C thicl } \\
\text { confid }\end{array}$ & $\begin{array}{l}\text { kness o } \\
\text { dence }\end{array}$ & differ & \\
\hline 0.61 & 0.78 & -0.05 & 2.69 & asured by & & & & & & & & & \\
\hline
\end{tabular}


Table XIII. Variation of the DLC Thicknesses (39 $\AA$ ) between Disks Measured by ESCA

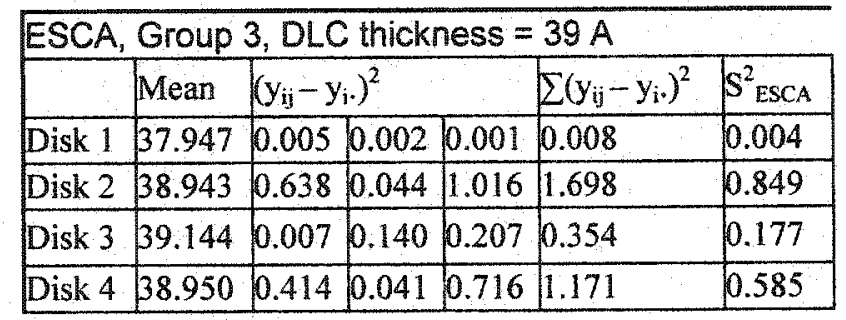

\begin{tabular}{|c|c|c|c|c|}
\hline & $S_{p}^{2}$ & $S_{p}$ & $t_{0}$ & $t_{0.005,4}$ Conclusion \\
\hline Disk1/Disk2 & 20.427 & 0.653 & 0.007 & $\begin{array}{l}\text { When } d_{0}=1 \AA,\left|t_{0}\right|<t_{0.005}, 4 \text {, meaning that the } \\
\text { 4.604 } \begin{array}{l}\text { DLC thickness difference between two disks is } \\
\text { within } 1 A \text { with } 99 \% \text { confidence }\end{array}\end{array}$ \\
\hline Disk1/Disk3 & 30.090 & 0.301 & 0.012 & $\begin{array}{l}\text { When } d_{o}=1.2 \AA,\left|t_{0}\right|<t_{0.005,4} \text {, meaning that the } \\
\text { DLC thickness difference between two disks is } \\
\text { within } 1.2 \AA \text { with } 99 \% \text { confidence }\end{array}$ \\
\hline Disk/Disk4 & 0.295 & 50.543 & -0.005 & $\begin{array}{l}\text { When } d_{o}=1 \AA,\left|t_{0}\right|<t_{0.005,4}, \text { meaning that the } \\
\text { 1.6 } C \text { thickness difference between two disks is } \\
\text { within } 1 \AA \text { with } 99 \% \text { confidence }\end{array}$ \\
\hline Disk2/Disk3 & 30.513 & 30.716 & -0.001 & $\begin{array}{l}\text { When } d_{0}=0.2 \AA,\left|t_{0}\right|<t_{0.005,4} \text {, meaning that the } \\
\text { DLC thickness difference between two disks is } \\
\text { within } 0.2 \AA \text { with } 99 \% \text { confidence }\end{array}$ \\
\hline Disk2/Disk4 & 40.717 & 70.847 & $7-0.009$ & $\begin{array}{l}\text { When } d_{o}=0 \AA,\left|t_{0}\right|<t_{0.005,4} \text {, meaning that the } \\
\text { DLC thickness difference between two disks is } \\
\text { within } 0 \AA \text { with } 99 \% \text { confidence }\end{array}$ \\
\hline Disk3/Disk4 & 40.38 & 10.617 & 7-0.01 & $\begin{array}{l}\text { When } d_{0}=0.2 \AA,\left|t_{o}\right|<t_{0.005,4} \text {, meaning that the } \\
\text { DLC thickness difference between two disks is } \\
\text { within } 0.2 \AA \text { with } 99 \% \text { confidence }\end{array}$ \\
\hline
\end{tabular}


Table XIV. Variation of the DLC Thicknesses ( $39 \AA$ ) between Disks Measured by AES

\begin{tabular}{|c|c|c|c|c|c|c|c|c|c|c|}
\hline & $\left(y_{i j}-y i\right)^{2}$ & & & & & & & & & \\
\hline Disk 1 & 0.020 & 0.004 & 0.056 & 0.002 & 0.000 & 0.076 & 0.599 & 0.255 & 0.005 & 0.186 \\
\hline Disk 2 & 0.113 & 0.003 & 0.779 & 0.028 & 0.004 & 0.061 & 0.200 & 0.022 & 0.107 & 0.011 \\
\hline Disk 3 & 0.000 & 0.000 & 0.030 & 0.083 & 0.190 & 0.003 & 0.466 & 0.006 & 0.030 & 0.174 \\
\hline Disk 4 & 0.031 & 0.101 & 0.254 & 0.123 & 0.591 & 0.003 & 0.066 & 0.143 & 0.143 & 0.003 \\
\hline & Mean & $\Sigma(y i j-y i) 2$. & $\mathrm{~S}_{\mathrm{AES}}^{2}$ & & & & & & & \\
\hline Disk 1 & 39.075 & 1.203 & 0.134 & & & & & & & \\
\hline Disk 2 & 39.801 & 1.330 & 0.148 & & & & & & & \\
\hline Disk 3 & 39.465 & 0.982 & 0.109 & & & & & & & \\
\hline Disk 4 & 39.911 & 1.459 & 0.162 & & & & & & & \\
\hline
\end{tabular}

\begin{tabular}{|c|c|c|c|c|c|}
\hline & $\mathrm{S}_{\mathrm{p}}^{2}$ & $\mathrm{~S}_{\mathrm{p}}$ & $t_{0}$ & $t_{0.005,18}$ & Conclusion \\
\hline $\begin{array}{l}\text { Disk1/ } \\
\text { Disk2 }\end{array}$ & 0.141 & 0.375 & -0.157 & 2.878 & $\begin{array}{l}\text { When } d_{0}=0.7 \AA,\left|t_{0}\right|<t_{0.005,18} \text {, meaning that the DLC } \\
\text { thickness difference between two disks is within than } \\
0.7 \AA \text { with } 99 \% \text { confidence }\end{array}$ \\
\hline $\begin{array}{l}\text { Disk1/ } \\
\text { Disk3 }\end{array}$ & 0.121 & 0.348 & 0.060 & 2.878 & $\begin{array}{l}\text { When } d_{0}=0.4 \AA,\left|t_{0}\right|<t_{0.005}, 18 \text {, meaning that the } D L C \\
\text { thickness difference between two disks is within } 0.4 \AA \\
\text { with } 99 \% \text { confidence }\end{array}$ \\
\hline $\begin{array}{l}\text { Disk/ } \\
\text { Disk4 }\end{array}$ & 0.148 & 0.385 & -0.212 & 2.878 & $\begin{array}{l}\text { When } d_{0}=0.8 \AA,\left|t_{0}\right|<t_{0.005,18} \text {, meaning that the } D L C \\
\text { thickness difference between two disks is within } 0.8 \AA \\
\text { with } 99 \% \text { confidence }\end{array}$ \\
\hline $\begin{array}{l}\text { Disk2/ } \\
\text { Disk3 }\end{array}$ & 0.128 & 0.358 & 0.222 & 2.878 & $\begin{array}{l}\text { When } d_{0}=0.2 \AA,\left|t_{0}\right|<t_{0.005}, 18 \text {, meaning that the DLC } \\
\text { thickness difference between two disks is within } 0.2 \AA \\
\text { with } 99 \% \text { confidence }\end{array}$ \\
\hline $\begin{array}{l}\text { Disk2/ } \\
\text { Disk4 }\end{array}$ & 0.155 & 0.394 & -0.058 & 2.878 & $\begin{array}{l}\text { When } d_{0}=0.1 \AA,\left|t_{0}\right|<t_{0.005}, 18 \text {, meaning that the DLC } \\
\text { thickness difference between two disks is within } 0.1 \AA \\
\text { with } 99 \% \text { confidence }\end{array}$ \\
\hline $\begin{array}{l}\text { Disk3/ } \\
\text { Disk4 }\end{array}$ & 0.136 & 0.368 & -0.278 & 2.878 & $\begin{array}{l}\text { When } d_{o}=0.4 \AA,\left|t_{0}\right|<t_{0.005,18} \text {, meaning that the } D L C \\
\text { thickness difference between two disks is within } 0.4 \AA \\
\text { with } 99 \% \text { confidence }\end{array}$ \\
\hline
\end{tabular}

